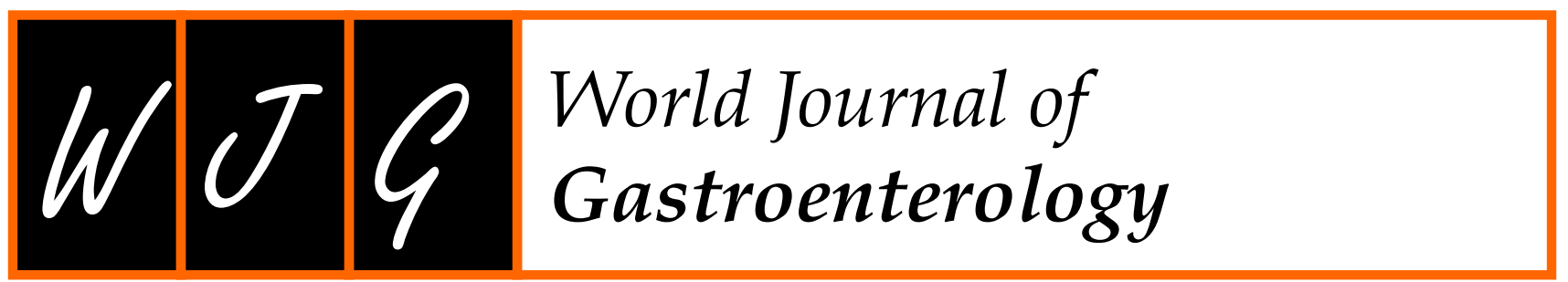

\title{
Effect of mild moxibustion on intestinal microbiota and NLRP6 inflammasome signaling in rats with post-inflammatory irritable bowel syndrome
}

\author{
Chun-Hui Bao, Chun-Ye Wang, Guo-Na Li, Yi-Lu Yan, Di Wang, Xiao-Ming Jin, Lu-Yi Wu, Hui-Rong Liu, \\ Xiao-Mei Wang, Zheng Shi, Huan-Gan Wu
}

\begin{abstract}
ORCID number: Chun-Hui Bao (0000-0002-9763-0046); Chun-Ye Wang (0000-0002-5991-6764); Guo$\mathrm{Na}$ Li (0000-0002-9984-7759); Yi-Lu Yan (0000-0001-9094-5291); Di Wang (0000-0002-8082-6544); XiaoMing Jin (0000-1234-2436-6523); LuYi Wu (0000-0002-7297-2509); HuiRong Liu (0000-0002-9697-5085); Xiao-Mei Wang

(0000-0003-1962-0827); Zheng Shi (0000-0003-0726-954X); Huan-Gan Wu (0000-0003-1725-6881).
\end{abstract}

Author contributions: $\mathrm{Bao} \mathrm{CH}$ and Wang CY contributed equally to this work; Wu HG and Bao CH conceived and designed this research; Bao $\mathrm{CH}$ and Wang $\mathrm{CY}$ wrote the manuscript; Li GN and Jin $\mathrm{XM}$ revised the manuscript; Bao $\mathrm{CH}$, Wang $\mathrm{CY}$, and Yan YL performed the experiments; Wu LY and Wang XM collected and analyzed the data; Li GN and Wang $D$ prepared the figures and tables; Shi Z and Liu HR supervised the research; all authors approved the final version of this article.

Supported by the National Natural Science Foundation of China, No. 81503656; and the National Key Basic Research Program of China (973 Program), No. 2015CB554501 and No. 2009CB522900.

\section{Institutional review board} statement: The study was reviewed and approved by the standardizing laboratory animal ethical review of Shanghai
Chun-Hui Bao, Chun-Ye Wang, Guo-Na Li, Yi-Lu Yan, Di Wang, Lu-Yi Wu, Hui-Rong Liu, Xiao-Mei Wang, Zheng Shi, Huan-Gan Wu, Key Laboratory of Acupuncture and Immunological Effects, Shanghai University of Traditional Chinese Medicine, Shanghai 200030, China

Xiao-Ming Jin, Stark Neurosciences Research Institute, Indiana University School of Medicine, Indianapolis, IN 46202, United States

Corresponding author: Huan-Gan $\mathrm{Wu}, \mathrm{PhD}$, Professor, Key Laboratory of Acupuncture and Immunological Effects, Shanghai University of Traditional Chinese Medicine, 650 South Wanping Road, Xuhui District, Shanghai 200030, China. wuhuangan@126.com

Telephone: +86-21-64644238

Fax: $+86-21-64644238$

\section{Abstract}

\section{BACKGROUND}

About one-third of refractory irritable bowel syndrome (IBS) cases are caused by gastrointestinal (GI) infection/inflammation, known as post-infectious/postinflammatory IBS (PI-IBS). Although it is known that intestinal microbiota and host NOD-like receptor family pyrin domain containing 6 (NLRP6) inflammsome signaling are closely related to PI-IBS and moxibustion has a therapeutic effect on PI-IBS, whether moxibustion regulates the intestinal flora and host NLRP6 events in PI-IBS remains unclear.

\section{AIM}

To examine the regulatory effect of moxibustion on intestinal microbiota and host NLRP6 inflammatory signaling in PI-IBS.

\section{METHODS}

Sprague-Dawley rats were divided into a normal control group, a model control group, a mild moxibustion group, and a sham mild moxibustion group. PI-IBS rats in the mild moxibustion group were treated with moxibusiton at bilateral Tianshu (ST 25) and Zusanli (ST36) for 7 consecutive days for 10 min each time. The sham group rats were given the same treatment as the mild moxibustion group except the moxa stick was not ignited. Abdominal withdrawal reflex (AWR) score was measured to assess the visceral sensitivity, and colon histopathology and ultrastructure, colonic myeloperoxidase (MPO) activity, and serum C-reactive protein (CRP) level were measured to evaluate low-grade 
University of Traditional Chinese Medicine.

Institutional animal care and use committee statement: All procedures involving animals were reviewed and approved by the standardizing laboratory animal ethical review of Shanghai University of Traditional Chinese Medicine (Ethical review code: SZY201711006)

Conflict-of-interest statement: The authors declare no conflict of interest related to this study.

Data sharing statement: No additional data are available.

ARRIVE guidelines statement: The ARRIVE guidelines have been adopted.

Open-Access: This article is an open-access article which was selected by an in-house editor and fully peer-reviewed by external reviewers. It is distributed in accordance with the Creative Commons Attribution Non Commercial (CC BY-NC 4.0) license, which permits others to distribute, remix, adapt, build upon this work non-commercially, and license their derivative works on different terms, provided the original work is properly cited and the use is non-commercial. See: http://creativecommons.org/licen ses/by-nc/4.0/

Manuscript source: Unsolicited manuscript

Received: April 15, 2019

Peer-review started: April 15, 2019

First decision: June 16, 2019

Revised: June 27, 2019

Accepted: July 5, 2019

Article in press: July 5, 2019

Published online: August 28, 2019

P-Reviewer: Day AS

S-Editor: Yan JP

L-Editor: Wang TQ

E-Editor: Zhang YL colonic inflammation in rats. The relative abundance of selected intestinal bacteria in rat feces was detected by $16 \mathrm{~S}$ rDNA PCR and the NLRP6 inflammsome signaling in the colon was detected by immunofluorescence, qRTPCR, and Western blot.

\section{RESULTS}

The AWR score was significantly decreased and the low-grade intestinal inflammation reflected by serum CRP and colonic MPO levels was inhibited in the mild moxibustion group compared with the sham group. Mild moxibustion remarkably increased the relative DNA abundances of Lactobacillus,

Bifidobacterium, and Faecalibacterium prausnitzii but decreased that of Escherichia coli in the gut of PI-IBS rats. Additionally, mild moxibustion induced mRNA and protein expression of intestine lectin 1 but inhibited the expression of IL-1 $\beta$, IL-18, and resistance-like molecule $\beta$ by promoting the NLRP6 and reducing the mRNA and protein expression of apoptosis-associated speck-like protein containing CARD (ASC) and cysteinyl-aspartate-specific proteinase 1 (Caspase-1). The relative DNA abundances of Lactobacillus, Bifidobacteria, Faecalibacterium prausnitzii, and Escherichia coli in each group were correlated with the mRNA and protein expression of NLRP6, ASC, and Caspase-1 in the colon.

\section{CONCLUSION}

These findings indicated that mild moxibustion can relieve low-grade GI inflammation and alleviate visceral hypersensitivity in PI-IBS by regulating intestinal microbes and controlling NLRP6 inflammasome signaling.

Key words: Moxibustion; Post-inflammation irritable bowel syndrome; Intestinal microbes; NLRP6 inflammasome; Intestinal inflammation; Visceral hypersensitivity; Traditional Chinese medicine

@The Author(s) 2019. Published by Baishideng Publishing Group Inc. All rights reserved.

Core tip: Moxibustion has been shown to have a therapeutic effect on postinfectious/post-inflammatory irritable bowel syndrome (PI-IBS). However, it is unclear whether moxibustion achieves its therapeutic effect by regulating intestinal microbiota and inflammatory responses in PI-IBS. In this study, we found that visceral hypersensitivity and low-grade intestinal inflammation in PI-IBS rats were significantly inhibited by 7-d mild moxibustion treatment. This treatment effect of moxibustion may be related to regulating the relative abundances of selected gut microbes and controlling NLRP6 inflammasome signaling.

Citation: Bao CH, Wang CY, Li GN, Yan YL, Wang D, Jin XM, Wu LY, Liu HR, Wang XM, Shi Z, Wu HG. Effect of mild moxibustion on intestinal microbiota and NLRP6 inflammasome signaling in rats with post-inflammatory irritable bowel syndrome. World $J$ Gastroenterol 2019; 25(32): 4696-4714

URL: https://www.wjgnet.com/1007-9327/full/v25/i32/4696.htm

DOI: https://dx.doi.org/10.3748/wjg.v25.i32.4696

\section{INTRODUCTION}

Irritable bowel syndrome (IBS) is a common functional gastrointestinal (GI) disorder with associated symptoms of abdominal pain and distention, dysphoria, and/or changes of defecation shape. The incidence of IBS is $11.2 \%$ worldwide and $5 \%-6 \%$ in China ${ }^{[1]}$. One-third of IBS cases are caused by GI infection/ inflammation, which is commonly defined as post-infectious/post-inflammatory IBS (PI-IBS) ${ }^{[2]}$. PI-IBS causes continual IBS symptoms after acute GI infection with Shigella, Escherichia coli, or Campylobacter jejuni ${ }^{[3,4]}$. Notably, the clinical symptoms (abdominal pain and diarrhea) ${ }^{[2]}$ of PI-IBS resemble those of diarrhea-predominant IBS (IBS-D) ${ }^{[5]}$.

Recent studies ${ }^{[6-8]}$ showed altered abundance and diversity of intestinal microflora in the GI tract of PI-IBS patients. The differences lie in the augmentation of Bacteroidetes, decline of Clostridium, and decrease in mucosal microbial diversity and 
stability, all of which are negatively correlated with the lymphocyte ratio in the mucosal lamina propria ${ }^{[7,8]}$. Barman et $a l^{[9]}$ showed that there was an approximately $95 \%$ decrease in the total number of bacteria in the cecum and colon after peroral Salmonella enterica serovar Typhimurium infection and the mice simultaneously suffered from severe diarrhea on day 7 post-infection. Moreover, alteration of intestinal microbiota triggers the intestinal mucosal immune system to cause ongoing lowgrade intestinal inflammation ${ }^{[10]}$. When pathogenic microorganisms invade and stimulate the gut, nucleotide-binding and oligomerization domain-like receptor (NLR) family pyrin domain 6 (NLRP6) binds to an apoptosis-associated speck-like protein containing CARD (ASC) and recruits a cysteinyl-aspartate-specific proteinase 1 (Caspase-1) that self-cleaves into activated Caspase-1. The activated Caspase-1 cleaves the precursors of the inflammatory cytokines interleukin $1 \beta$ (pro-IL-1 $\beta$ ) and IL-18 (pro-IL-18) to form active mature peptides, which are delivered extracellularly and thus cause low-grade intestinal inflammation ${ }^{[11]}$. Moreover, IL-18 induces the expression of intestine lectin 1(ITLN1) and resistance-like molecule $\beta$ (RELM $\beta$ ), both of which play pivotal roles in gut inflammatory response. ITLN1 is associated with secretory function of intestinal goblet cells and is involved in gut immunity while RELM $\beta$ has a positive correlation with the level of gut inflammation ${ }^{[12-14]}$.

Conventional treatments for IBS have limitations such as a high risk of side effects and long-term drug administration ${ }^{[15,16]}$. Moxibustion treatment has effects in disease amelioration and improvement of life quality of IBS-D patients, and provides more benefits than pharmacotherapy ${ }^{[16,17]}$. Our previous study found that moxibustion decreased gut relative DNA abundances of Prevotella, Bacteroides, and Clostridium XI, increased those of Lactobacillus and Clostridium XIVa, and improved the gut microbiota alpha diversity in a chronic visceral pain model of IBS in rats ${ }^{[18]}$. Given the importance of NLRP6 inflammasome signaling in the intestinal mucosa in maintaining the stability of gut microbiota and intestinal homeostasis ${ }^{[19,20]}$, this study tested the hypothesis that moxibustion may relieve visceral hypersensitivity of PI-IBS by regulating intestinal microbiota and NLRP6 inflammasome signaling mediated GI tract inflammation.

\section{MATERIALS AND METHODS}

This experiment protocol was approved by the standardizing laboratory animal ethical review of Shanghai University of Traditional Chinese Medicine and implemented according to experimental protocol completely (Ethical review code: SZY201711006).

\section{Animals and model preparation}

Pathogen-free male Sprague-Dawley rats $(150 \pm 20 \mathrm{~g})$ were fed adaptively for $7 \mathrm{~d}$ with drinking water ad libitum. All rats were provided by the Animal Experimental Center of Shanghai University of Traditional Chinese Medicine [License number: SCXK (Hu) 2017-0005]. The rats were randomly divided into a normal control group and a model control group. PI-IBS was induced in rats with 2,4,6-trinitrobenzenesulfonic acid $(\text { TNBS })^{[21]}$. No treatment was given to the normal control group. One normal rat and two model rats were randomly selected on each of the days 7, 14, 21, and 28 to observe their colonic mucosal structure and histopathology. Abdominal withdrawal reflex $(A W R)^{[22]}$ scores were assessed to determine whether the model was successfully established. The AWR scores were assessed under the induction of balloon dilation for colorectal distension (CRD). All rats were fasted for $12 \mathrm{~h}$ except for drinking water. A cotton swab was used to stimulate the contraction of the anus for promoting defecation. A small balloon dipped in liquid paraffin was then slowly inserted into the colon to $3 \mathrm{~cm}$. Subsequently, the rats were fixed on a table and given $20,40,60$, and $80 \mathrm{mmHg}$ pressure stimulation successively. The Al-Chaer method was used to evaluate the criterion-referenced AWR score ${ }^{[22]}$. The criteria (score) were: 0 , no reaction to CRD; 1 , the body remains immobile or head moves slightly; 2 , abdominal muscle contraction; 3 , the abdominal wall lifts from the bottom and contracts obviously; and 4, body arching along with the pelvic and scrotum lifting. The same pressure stimulations were performed three times and the average score was taken as the final score.

\section{Group division and moxibustion implementation}

The TNBS-treated PI-IBS rats were further subdivided into a model control group, a mild moxibustion group, and a sham moxibustion group. A normal control group was also established. For mild moxibustion, bilateral Zusanli (ST 36) and Tianshu (ST 25) acupoints were selected based on the locations described in Experimental Acupuncture $^{[23]}$, which are similar to our previous studies ${ }^{[24,25]}$. A moxa stick of $5 \mathrm{~mm}$ 
in diameter was ignited and placed $2-3 \mathrm{~cm}$ above the selected points for $10 \mathrm{~min}$ per day for $7 \mathrm{~d}$ of continuous treatment. The sham moxibustion group was given the same treatment as the mild moxibustion group except that an unlit moxa stick was used (Figure 1). The model control group and the normal control group were given the same fixation (The forelimbs and hind limbs of the rats were fixed on the fixation device) as the mild moxibustion group without any intervention.

\section{AWR score}

After the intervention was finished, the AWR scores were assessed as described above.

\section{Protocols for collecting specimens of feces, serum, and colonic tissues}

Rat feces were collected after the AWR scores were assessed. A swab was used to touch the perianal skin of the rats to collect 2-3 capsules of feces, which were then immediately stored in freezing tubes at $-80{ }^{\circ} \mathrm{C}$. Anesthesia was performed by intraperitoneal injection of $2 \%$ sodium barbiturate $(0.3 \mathrm{~mL} / 100 \mathrm{~g})$. Blood samples collected from the abdominal aorta were transferred into a cryogenic microcentrifuge tube after 1-h standstill and centrifuged for $20 \mathrm{~min}(3000 \mathrm{rpm})$ to collect the serum. Distal colonic tissues ( $6 \mathrm{~cm}$ above the first lymph node of the anus) were rinsed with normal saline to remove the surrounding connective tissue and fat, and then the lesions in the colonic mucosa were scored and photographed. The criteria of colonic mucosa damage score was according to Wallace et al ${ }^{[26]}$. After scoring, the colonic tissues were then stored in $4 \%$ paraformaldehyde or liquid nitrogen.

\section{Hematoxylin and eosin (HE) staining}

The colonic tissues that were drained from $4 \%$ paraformaldehyde were embedded in paraffin and cut into $4 \mu \mathrm{m}$ slices. The sections were processed with xylene I and xylene II for 20 min successively. Subsequently, the sections were hydrated with anhydrous ethanol, $90 \%$ ethanol, $80 \%$ ethanol, and $70 \%$ ethanol sequentially with 3 min of treatment of each round. Then sections were treated with hematoxylin stain for $1.5 \mathrm{~min}, 1 \%$ hydrochloric acid alcohol for $4 \mathrm{~s}$, and eosin for $2 \mathrm{~min}$. The histopathological findings were observed under an optical microscope and analyzed according to the criteria in the literature published by Park et al ${ }^{[27]}$. The histopathological score includes severity of inflammation, extent of inflammation, and crypt damage, with a score of 0-9.

\section{Enzyme linked immunosorbent assay (ELISA)}

The serum C-reactive protein (CRP) levels and myeloperoxidase (MPO) activities in colonic tissues of rats were measured by ELISA (Shanghai Yuanye Biological Co., Shanghai, China). The concentrations of diluted serum samples were $1800 \mu \mathrm{g} / \mathrm{L}, 1200$ $\mu \mathrm{g} / \mathrm{L}, 600 \mu \mathrm{g} / \mathrm{L}, 300 \mu \mathrm{g} / \mathrm{L}, 150 \mu \mathrm{g} / \mathrm{L}$, and $50 \mu \mathrm{l}$ per well, respectively. The concentrations of homogenized colonic tissues were $120 \mathrm{U} / \mathrm{L}, 80 \mathrm{U} / \mathrm{L}, 40 \mathrm{U} / \mathrm{L}, 20$ $\mathrm{U} / \mathrm{L}$, and $10 \mathrm{U} / \mathrm{L}$ with $50 \mu \mathrm{L}$ of equal sampling volume.

\section{Extraction of total DNA of gut microbiota}

Thawing feces after freezing $(0.2 \mathrm{~g})$ were dissolved into $1.5 \mathrm{~mL}$ of $0.05 \mathrm{M}$ phosphate buffered saline (PBS), blended for $5 \mathrm{~min}$, and centrifuged three times (1000 rpm; 15 $\mathrm{min} /$ time). The supernatant was collected and then centrifuged for another $10 \mathrm{~min}$ (14000 rpm). The supernatant was then removed, and $1 \mathrm{~mL}$ of PBS was added into the precipitate and then centrifuged for $5 \mathrm{~min}(14000 \mathrm{rpm})$. The above procedures were repeated five times.

The precipitate was washed with $1 \mathrm{~mL}$ of water, then $100 \mu \mathrm{L}$ of sterile water and TritonX-100 were added to the precipitate to mix and lyse the cells. Then, the sample was centrifuged for $15 \mathrm{~s}$ (14000 rpm). Two hundred microliters of supernatant from the lysate was taken, extracted by phenol and chloroform (1:1) for $10 \mathrm{~s}$, and centrifuged for $15 \mathrm{~s}$ (14000 rpm). About 2.5-fold of supernatant volume cold ethanol was added into the collected supernatant. The mixture was incubated at $-20^{\circ} \mathrm{C}$ for $1 \mathrm{~h}$ and centrifuged for $1 \mathrm{~min}(14000 \mathrm{rpm})$. The supernatant was discarded, and cold ethanol was added to the precipitate again, incubated at $-20^{\circ} \mathrm{C}$ for $1 \mathrm{~h}$, and centrifuged for $1 \mathrm{~min}(14000 \mathrm{rpm})$. The supernatant was discarded and the DNA precipitate was dried, dissolved with $50 \mu \mathrm{L}$ of sterile water, and stored at $-20{ }^{\circ} \mathrm{C}$ in a freezer.

\section{S rDNA PCR}

According to the literature ${ }^{[28]}$, the bacterial abundance of Escherichia coli in patients with IBS is significantly higher than that in healthy people, while the abundance of Lactobacillus is significantly reduced. The abundance of Bifidobacterium in the gut of IBS patients is 1.5 times less than that of healthy people ${ }^{[29]}$, and the Faecalibacterium 


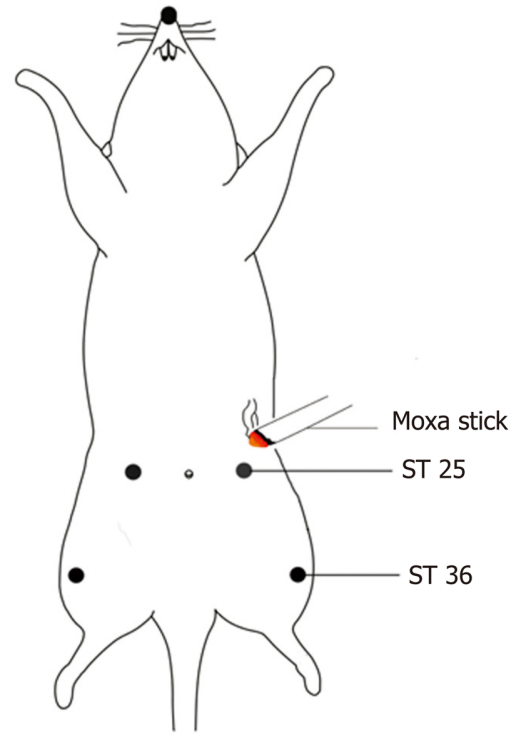

Mild moxibustion group

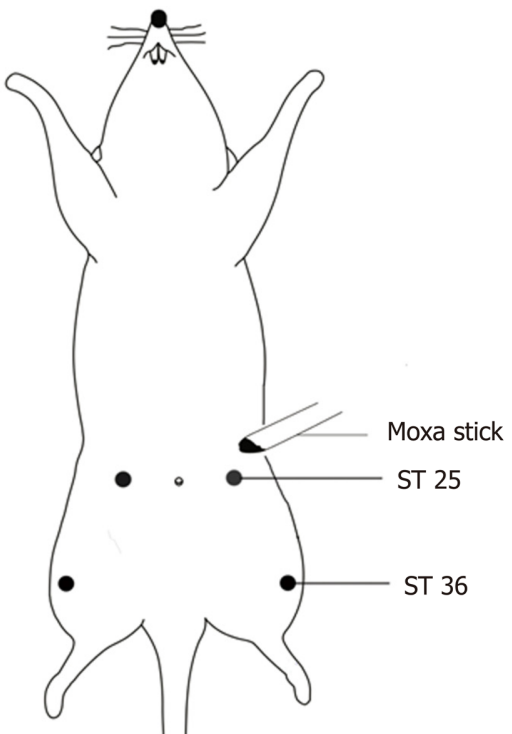

Sham moxibustion group

Figure 1 Diagram of moxibustion in rats. Rats were immobilized on a fixing frame. A: A moxa stick of $5 \mathrm{~mm}$ in diameter was ignited and placed 2-3 cm above the bilateral Zusanli (ST26) and Tianshu (ST25) for 10 min per day with $7 \mathrm{~d}$ of continuous treatment in the mild moxibustion group; $\mathrm{B}$ : The sham moxibustion group was given the same treatment as the mild moxibustion group except that moxibustion was treated with an unlit moxa stick.

prausnitzii and its cultural supernatant can relieve the intestinal inflammation ${ }^{[30]}$. Therefore, Lactobacillus, Bifidobacterium, Faecalibacterium prausnitzii, and Escherichia coli were selected as the four targeted microbes for research. 16S rDNA PCR was applied for testing the DNA relative abundance of selected bacteria. The isolated DNA was amplified by real-time PCR with a total volume of $25 \mu \mathrm{L}$ recipe: SYBR Green Mix 12.5 $\mu \mathrm{L}$, primer F $0.5 \mu \mathrm{L}$, primer $\mathrm{R} 9.5 \mu \mathrm{L}$, double distilled water $9.5 \mu \mathrm{L}$, and cDNA template $2 \mu \mathrm{L}$. SYBR Green PCR kit was purchased from ThermoFisher (K0223) and the PCR purification kit was purchased from Axygen (AP-GX-50). The primer sequences are listed in Table 1 . Reaction conditions were: $95^{\circ} \mathrm{C}$ for $10 \mathrm{~min} ; 40$ cycles of $95^{\circ} \mathrm{C}$ for $15 \mathrm{~s}$ and $60{ }^{\circ} \mathrm{C}$ for $45 \mathrm{~s} ; 95^{\circ} \mathrm{C}$ for $15 \mathrm{~s} ; 60^{\circ} \mathrm{C}$ for $1 \mathrm{~min} ; 95^{\circ} \mathrm{C}$ for $15 \mathrm{~s}$; and 60 ${ }^{\circ} \mathrm{C}$ for $15 \mathrm{~s}$. ABI Prism 7300 SDS software was used to analyze the data.

\section{qRT-PCR}

The mRNA expression of NLRP6, ASC, Caspase-1, IL-1 $\beta$, IL-18, ITLN1, and RELM $\beta$ was detected by qRT-PCR. One milliliter of colonic tissue was added into a homogenate tube containing Trizol reagent, and total RNA was extracted according to the manufacturer's instruction (1596-026; Invitrogen). A volume of $25 \mu \mathrm{L}$ cDNA reaction recipe was prepared in a sequence of RNA-Primer Mix $12 \mu \mathrm{L}, 5 \times \mathrm{RT}$ Reaction Buffer $5 \mu \mathrm{L}, 25 \mathrm{mM}$ dNTPs $1 \mu \mathrm{L}, 25 \mathrm{U} / \mu \mathrm{L}$ RNase Inhibitor $1 \mu \mathrm{L}, 200 \mathrm{U} / \mu \mathrm{L} \mathrm{M}$ MLV Rtase $1 \mu \mathrm{L}$, Oligo (dt) 18 primer $1 \mu \mathrm{L}$, and DEPC water $4 \mu \mathrm{L}$. The products for qPCR were made in a reaction system containing SYBRGreen Mix $12.5 \mu \mathrm{L}$, primer $\mathrm{F}$ $0.5 \mu \mathrm{L}$, primer $\mathrm{R} 0.5 \mu \mathrm{L}$, ddH $\mathrm{O}_{2} \mathrm{O} 9.5 \mu \mathrm{L}$, and cDNA template $2 \mu \mathrm{L}$. SYBR Green PCR KIT was purchased from Thermo (K0223), and the Retroscript kit was purchased from Fermentas (k1622). The primer sequences are listed in Table 2. Reaction conditions were: $95^{\circ} \mathrm{C}$ for $10 \mathrm{~min} ; 40$ cycles of $95^{\circ} \mathrm{C}$ for $15 \mathrm{~s}$ and $60{ }^{\circ} \mathrm{C}$ for $45 \mathrm{~s} ; 95^{\circ} \mathrm{C}$ for $15 \mathrm{~s} ; 60$ ${ }^{\circ} \mathrm{C}$ for $1 \mathrm{~min} ; 95^{\circ} \mathrm{C}$ for $15 \mathrm{~s}$; and $60^{\circ} \mathrm{C}$ for $15 \mathrm{~s}$. ABI Prism 7300 SDS software was used to analyze the data.

\section{Western blot analysis}

Western blot was performed to test the protein expression of NLRP6, ASC, Caspase-1, IL-1 $\beta$, IL-18, ITLN1, and RELM $\beta$ in the colonic tissue. The colon tissue stock was taken out from liquid nitrogen. The tissue was weighed, chopped, and placed in a homogenate tube. Then, a lysis fluid (containing protease and phosphatase inhibitors) was added to the sample tube to fully lyse the cells at $4{ }^{\circ} \mathrm{C}$. The cells were scraped into a $1.5 \mathrm{~mL}$ Eppendorf tube, heated at $95^{\circ} \mathrm{C}$, and then centrifuged for $15 \mathrm{~min}(12000$ $\mathrm{rpm})$. The supernatant was harvested for protein quantification. The dilutions of primary antibodies of NLRP6 (Santa Cruz, SC-376434), ASC (Invitrogen, PA5-50915), 
Table 1 Primers used for amplification of selective intestinal microbiota

\begin{tabular}{lll}
\hline Microorganism & \multicolumn{2}{c}{ Base sequence } \\
\hline Lactobacillus & Primer F & 5'-ACGGGAGGCAGCAGTAGGGA-3' \\
& Primer R & 5'-AGCCGTGACTTTCTGGTTGATT-3' \\
Bifidobacterium & Primer F & 5'-GATTCTGGCTCAGGATGAACGC-3' \\
& Primer R & 5'-CTGATAGGACGCGACCCCAT-3' \\
Faecalibacterium_prausnitzii & Primer F & 5'-AGATGGCCTCGCGTCCGA-3' \\
& Primer R & 5'-CCGAAGAACCTTCTTCCTCC-3' \\
Escherichia_coli & Primer F & 5'-CATGCCGCGTGTATGAAGAA-3' \\
& Primer R & 5'-CGGGTAACGTCAATGAGCAAA-3' \\
\hline
\end{tabular}

Caspase-1 (Abcam, Ab1872), IL-1ß (Abcam, Ab9722), IL-18 (Abcam, Ab191860), and GAPDH (CST, \#5174) were 1:100, 1:1000, 1:500, 1:1000, 1:1000, and 1:2000, respectively.

\section{Immunofluorescence}

The protein expression and location of NLRP6, ASC, and Caspase-1 in colonic tissue were studied by immunofluorescence. The paraffin sections of colon tissue were dried at $60{ }^{\circ} \mathrm{C}$, plastered with xylene-wax twice, repaired with $0.01 \mathrm{M}$ of sodium citrate buffer solution for 15 min after gradient alcohol dehydration, and finally washed with PBS three times. The primary antibody of NLRP6 was goat anti-mouse IgG [Biyuntian Biotechnology Co., Ltd (A0428)] labelled with Alexa Fluor 488; the diluted concentration was 1:500. The primary antibodies of ASC and Caspase-1 were goat anti-rabbit IgG [Biyuntian Biotechnology Co., Ltd (A0423)] labelled with Alexa Fluor 488; the dilution was $1: 100$ and incubation temperature was $4{ }^{\circ} \mathrm{C}$. The dilutions of fluorescent secondary antibody of NLRP6, ASC, and Caspase-1 were 1:200, 1:500, and 1:200, respectively, with 30 min incubation. The protein expression of NLRP6, ASC, and Caspase- 1 in the intestinal mucosa was observed under a laser confocal microscope.

\section{Statistical analysis}

Statistical analyses were performed using SPSS v21.0 software. Serum CRP level, colonic MPO activity, relative bacterial abundance, and colonic mRNA and protein expression of NLRP6, ASC, Caspase-1, IL-1 $\beta$, IL-18, ITLN1, and RELM $\beta$ are represented as the mean \pm SD. These data were analyzed by one-way analysis of variance (ANOVA) for the differences between groups, and the least significant difference test for pairwise comparisons. AWR score, colonic mucosa damage score, and histopathological score are shown as medians (P25, P75). These data were analyzed by the nonparametric Kruskal-Wallis test. The correlations were measured by Pearson correlation coefficient. $P<0.05$ was set as the threshold of statistical significance $^{[31,32]}$.

\section{RESULTS}

Sixty rats were randomly divided into a normal control group $(n=14)$ and a model control group $(n=46)$. One normal rat and two model rats were randomly selected on each of the days $7,14,21$, and 28 to establish a PI-IBS model. During the preparation of the model, one rat died and the remaining rats in the model control group were further subdivided into a model control group $(n=13)$, a mild moxibustion group ( $n$ $=12)$, and a sham moxibustion group $(n=12)$. Finally, 10 rats in each of the three groups were randomly selected, and with the 10 rats in the normal control group, a total of 40 rats were included in the final statistical analysis.

\section{PI-IBS model}

The colonic mucosal surfaces of normal rats on days 7, 14, 21, and 28 were smooth and the mucosa rugae were clear with full shape and moderate thickness (Figure 2A). The HE staining results demonstrated that the colonic mucosa of the model control group had mild hyperemia and edema damage, and the glands appeared neatly arranged (Figure 2B). Compared to the normal control group, the colonic tissue of rats in the model control group on day 7 became significantly thickened, congested, and swollen with no mucosa rugae or ulcers. As seen under the microscope, most of the glandular structures disappeared, the mucosa and submucosa had severe infiltration of 


\begin{tabular}{lll}
\hline mRNA & \multicolumn{2}{l}{ Base sequence } \\
\hline NLRP6 & Primer A & 5'-AAGGTGAAGGAGAGGAATG-3' \\
& Primer B & 5'-GAAGAGCCGATTGAAAGTG-3' \\
ASC & Primer A & 5'-TGCTGGATGCTCTGTATGG-3' \\
& Primer B & 5'-CAAGTAGGGCTGTGTTTGC-3' \\
Caspase-1 & Primer A & 5'-GACAAGCCCAAGGTTATC-3' \\
& Primer B & 5'-GGCCTTCTTAATGCCATC-3' \\
IL-1 $\beta$ & Primer A & 5'-AAGGTGAAGGAGAGGAAT-3' \\
& Primer B & 5'-GAAGAGCCGATTGAAAGTG-3' \\
IL-18 & Primer A & 5'-TGCTGGATGCTCTGTATGG-3' \\
& Primer B & 5'-CAAGTAGGGCTGTGTTGC-3' \\
GAPDH & Primer A & 5'-GTCGGTGTGAACGGATTTG-3' \\
& Primer B & 5'-TCCCATTCTCAGCCTTGAC-3' \\
\hline
\end{tabular}

inflammatory cells, and the submucosa was congested with edema.

By day 28, the thickness of the colonic tissue was gradually reduced, and the hyperemia and edema were relieved, meanwhile the mucosal rugae were clear and had returned to normal. The gland boundary was clear and neat under the microscope, the lamina propria had less inflammatory cell infiltration than that on day 7 , and the submucosa exhibited mild hyperemia and edema.

AWR scores were calculated for the normal control group and model control group on day 28. Compared with the normal control group, the rats in the model control group had significantly higher AWR scores under $20 \mathrm{mmHg}, 40 \mathrm{mmHg}$, and 60 $\mathrm{mmHg}$ pressure stimulation $(P<0.01)$, respectively, which indicated that the model control group had obviously increased gut sensitivity (Figure 2C). The higher AWR scores and alterations in colonic mucosal histopathology indicated higher gut sensitivity after low-grade inflammation and the successful establishment of the PIIBS model.

\section{AWR scores}

The model control group had significantly higher AWR scores compared to the normal control group under $20 \mathrm{mmHg}, 40 \mathrm{mmHg}$, and $60 \mathrm{mmHg}$ pressure stimulation, respectively $(P<0.01)$. The rats in the mild moxibustion group possessed lower AWR scores than those of the model control group under $20 \mathrm{mmHg}, 40 \mathrm{mmHg}$, and $60 \mathrm{mmHg}$ pressure stimulation, respectively $(P<0.01)$. The sham moxibustion group also exhibited lower AWR scores than the model control group, but there was no significant difference between the two groups in AWR scores under different stimulating pressures $(P>0.05)$ (Figure $3 \mathrm{~A})$. These results indicated that moxibustion significantly alleviated gut hypersensitivity and increased pain threshold of rats in the model control group. This effect was significantly better than that of sham moxibustion.

\section{Colonic mucosal damage}

The colonic mucous membrane of normal rats was smooth and the mucosal ruga were clear and had an integral shape with moderate thickness. The model and sham moxibustion groups displayed thicker colonic tissues than normal rats with visible pathological changes such as mild hyperemia and edema without ulcers. The mild moxibustion group had smooth colonic mucous membranes and clear and integralshaped mucosal rugae. The bowel walls of rats in the mild moxibustion group were slightly thicker than those of the normal control group, but still thinner than those of the model control group and sham moxibustion group. Furthermore, the bowel walls of rats in the mild moxibustion group had mild hyperemia but no ulcers (Figure 3B). The rats of the model control group, the mild moxibustion group, and the sham moxibustion group had higher colonic mucosa damage scores than those of the normal control group. However, there was no significant difference among all these groups (Figure 3C).

\section{Colonic histopathology}

Microscopically, the colonic mucous membrane of normal rats was smooth, the glands were neatly arranged with no hyperemia or edema, and no inflammatory cell infiltration was observed. The model control group had neatly integrated membrane 
A Normal control group

on day 7
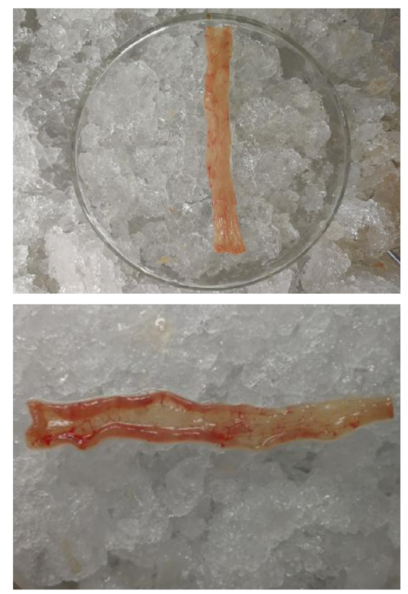

Model control group on day 7

B

Normal control group on day 7

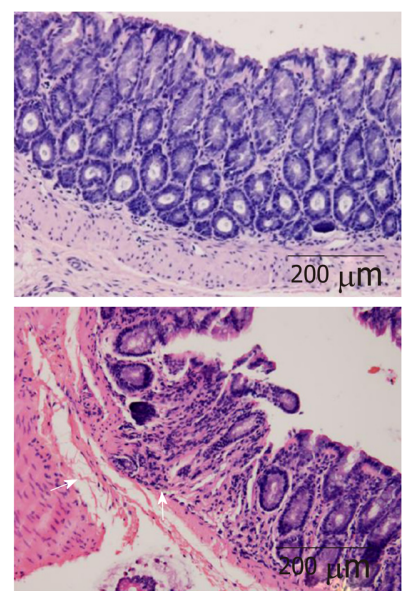

Model control group

on day 7
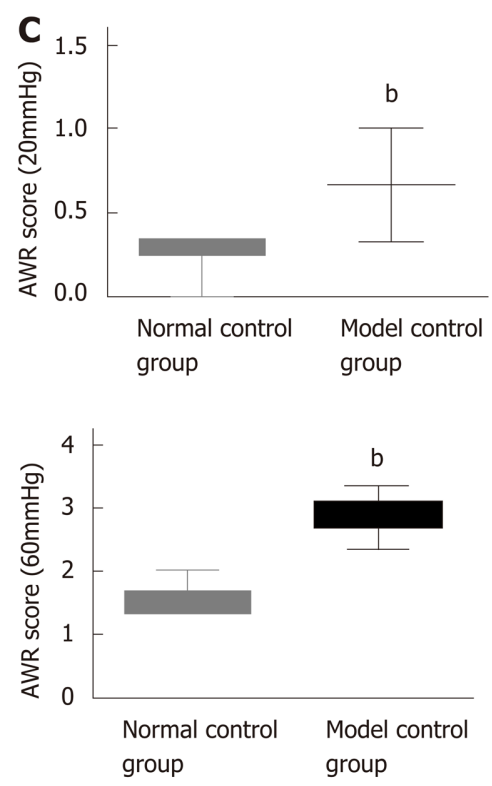

Normal control group

on day 14
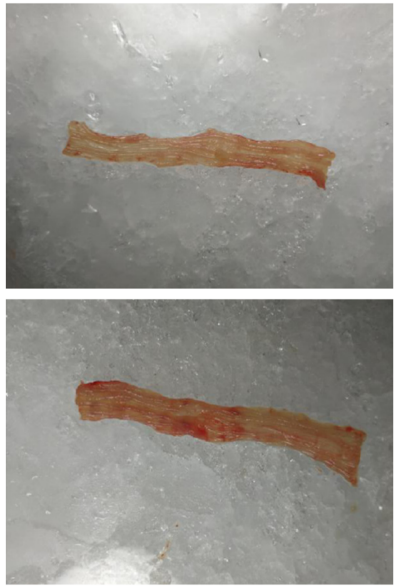

Model control group

on day 14

Normal control group

on day 14

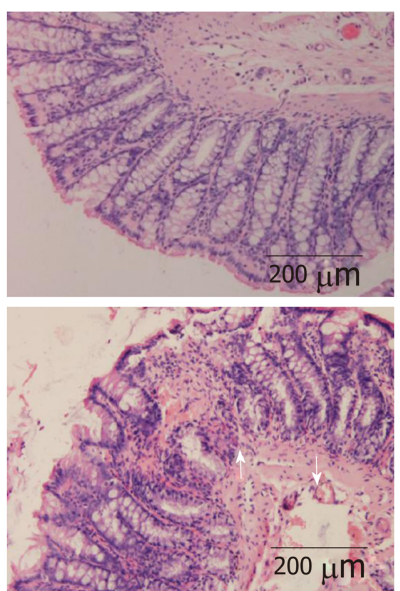

Model control group

on day 14
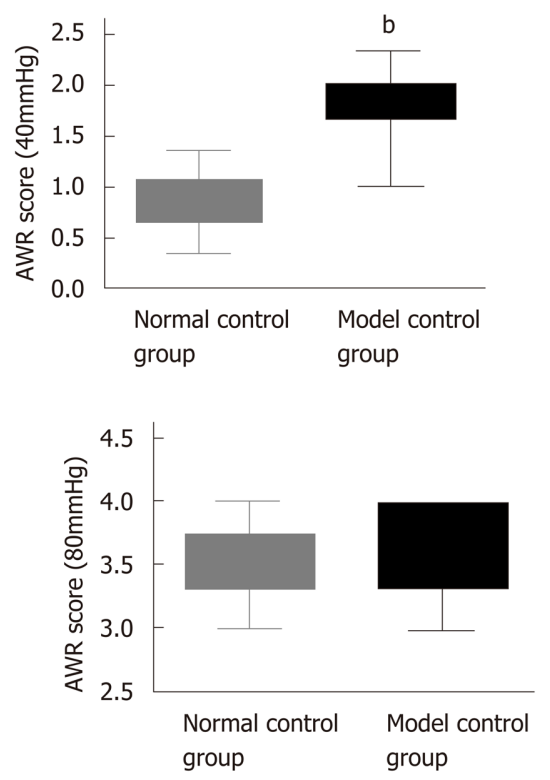

Figure 2 A rat post-infectious/post-inflammatory irritable bowel syndrome model established by 2,4,6-trinitrobenzenesulfonic acid induction. A: Gross structure; B: Pathology of the normal control group and model control group on days 7, 14, 21, and 28; C: Abdominal withdrawal reflex scores of the normal and model control groups under different pressure stimulations on day 28 after model generation. ${ }^{b} P<0.01$ vs normal control group. AWR: Abdominal withdrawal reflex. 

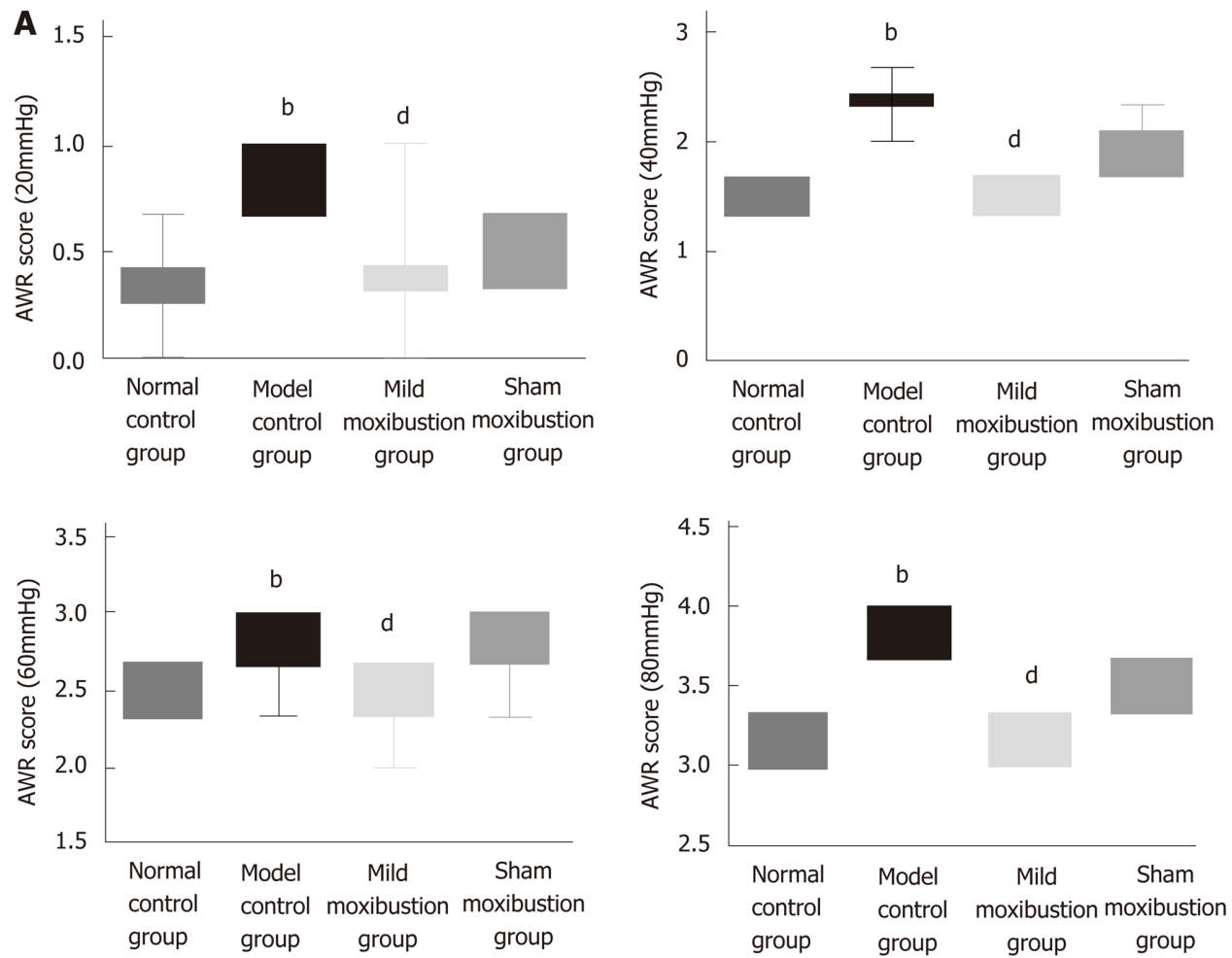

B

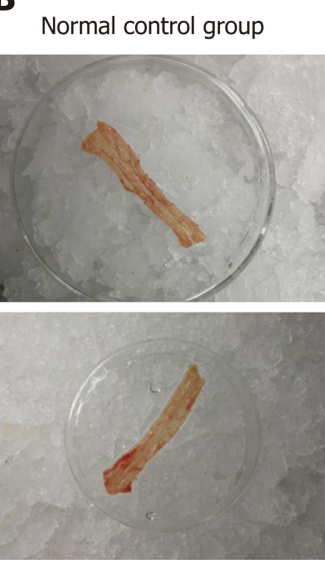

Mild moxibustion group

D Normal control group
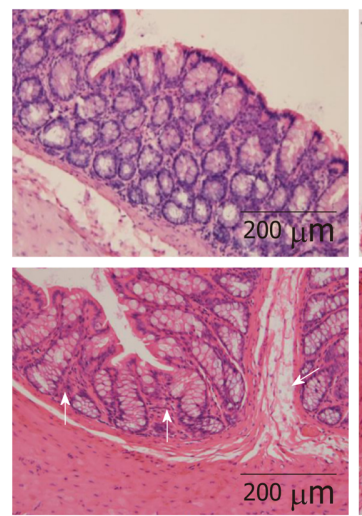

Mild moxibustion group
Model control group
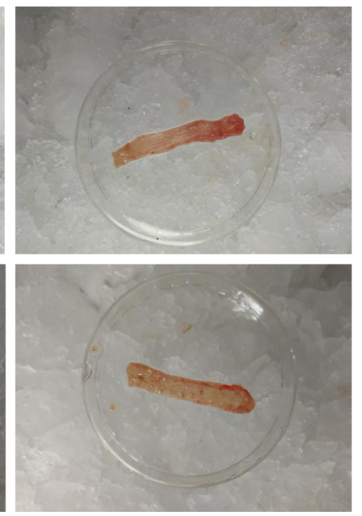

Sham moxibustion group

Model control group
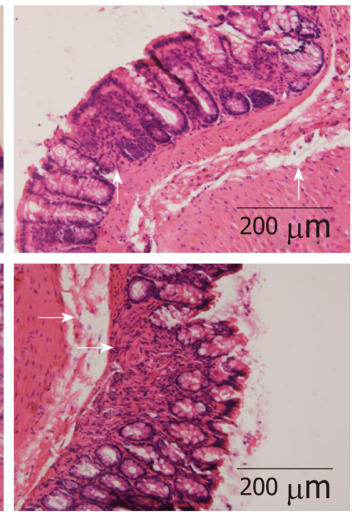

Sham moxibustion group
C

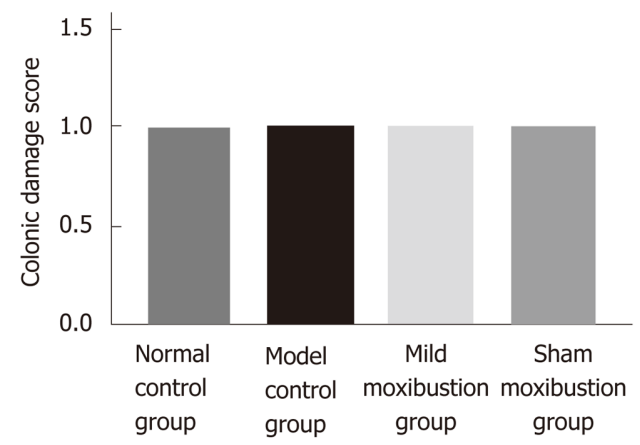

E

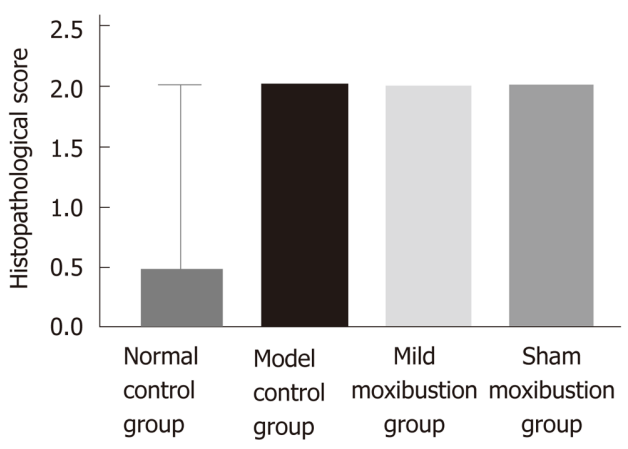

Figure 3 Effects of mild moxibustion on abdominal withdrawal reflex scores and low-grade inflammation of the colon in each group. A: Abdominal withdrawal reflex score; B: Observed gross structure; C: Histological score; D: Observed histopathology; E: Pathological score. ${ }^{b} P<0.01$ vs normal control group; ${ }^{\mathrm{d}} P$ $<0.01$ vs model control group. AWR: Abdominal withdrawal reflex. 
with a messy gland arrangement, and structure of the glands could not be identified under the microscope. The mucosa and submucosa were infiltrated with a small number of inflammatory cells, giving an appearance of submucosal hyperemia and edema. The mild moxibustion group harbored integrated membrane with the glands neatly arranged, and no inflammatory infiltration was observed. The submucosa of some rats of the mild moxibustion group was mildly congested and swollen. The sham moxibustion group displayed similar colonic pathology as the PI-IBS model. These observations suggested that mild moxibustion ameliorated the intestinal mucosal pathological score of PI-IBS rats and displayed better efficiency than sham moxibustion in the treatment of PI-IBS rats (Figure 3D). Both the model control group and the sham moxibustion group had higher histopathological scores than the normal control group and the mild moxibustion group. However, there was no statistical difference among all these groups (Figure 3E).

\section{Colonic ultrastructure}

The colonic ultrastructure of rats in the normal control group showed neat and regular shaped villi, and close links between epithelial cells, and the mitochondria were oval shaped with clear and regular cristae. In the model control group, however, the colonic villi were partially missing, and the epithelial space in model control group rats became wider than that in the normal control group. The number of desmosomes decreased, the mitochondria became swollen with larger sizes, the inner crests were blurred, and some vacuoles appeared.

Colonic villi of rats in the mild moxibustion group were neat with regular shape and length. No significant increase in epithelial cell gaps was observed, the number of desmosomes increased, and the shapes of the mitochondria and cristae were regular and clear. Rats in the sham moxibustion group demonstrated almost the same alterations as the model control group. These results indicated that mild moxibustion improved the ultrastructure of the colonic tissues to a far greater extent than that of sham moxibustion (Figure 4).

\section{Serum CRP levels and colonic MPO activity}

The model control group had significantly higher colonic MPO activities and serum CRP levels than the normal control group $(P<0.01)$, while the mild moxibustion group had significantly lower colonic MPO activities and serum CRP levels $(P<0.01)$ than the model control group. The sham moxibustion group also had decreased colonic MPO activities and serum CRP levels than the model control group, but this difference was not statistically significant. In contrast, the mild moxibustion group had significantly lower colonic MPO activities and serum CRP levels than the sham moxibustion group $(P<0.01)$ (Figure 5). These results revealed that mild moxibustion significantly decreased colonic MPO activities and serum CRP levels, relieved intestinal inflammation, and had a better therapeutic effect than the sham moxibustion group in the treatment of PI-IBS rats.

\section{Relative bacterial abundance in the intestine}

Sequencing analysis indicated that relative DNA abundances of Lactobacillus, Bifidobacteria, and Faecalibacterium prausnitzii in gut microbiota community were remarkably lower in the model control group than in the normal control group $(P<$ $0.01)$, and the DNA abundance of Escherichia coli was significantly higher $(P<0.01)$. Compared with the model control group, the relative DNA abundances of the Lactobacillus, Bifidobacteria, and Faecalibacterium prausnitzii in the mild moxibustion group were significantly increased $(P<0.05)$ while the relative DNA abundance of Escherichia coli was significantly decreased $(P<0.01)$. The relative DNA abundances of the four aforementioned kinds of bacteria in the sham moxibustion group were almost the same as those of the model control group.

Compared with the sham moxibustion group, the mild moxibustion group had higher relative DNA abundances of Lactobacillus, Bifidobacteria, and Faecalibacterium prausnitzii $(P<0.01)$ and lower DNA abundance of Escherichia coli $(P<0.01)$ (Figure 6). These findings suggested that mild moxibustion significantly increased the relative DNA abundances of intestinal Lactobacillus, Bifidobacterium, and Faecalibacterium prausnitzii but reduced the relative abundance of Escherichia coli in the gut microbiota of PI-IBS rats, which was superior to sham moxibustion in adjusting the equilibrium of relative gut microbiome.

\section{The mRNA and protein expression of NLRP6, ASC, and Caspase-1}

The model control group displayed significantly lower mRNA and protein expression of NLRP6 and markedly higher mRNA and protein expression of ASC and Caspase-1 in comparison with the normal control group $(P<0.01)$. There was no statistical significance between the model control group and mild moxibustion group in 
Normal control group $4800 \times$
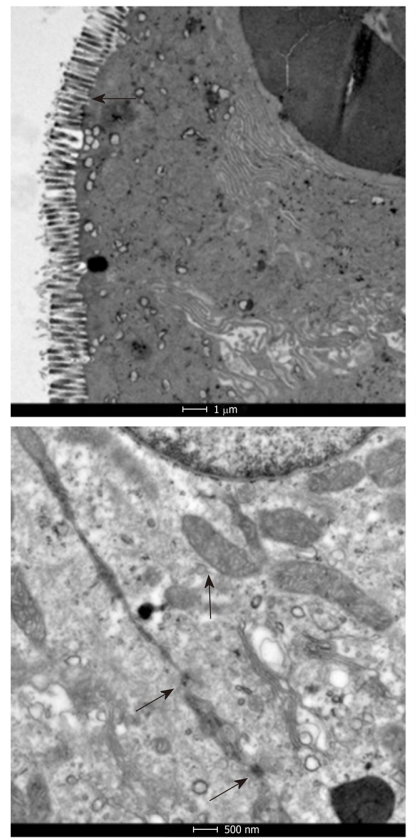

Normal control group $9300 \times$
Model control group $4800 \times$
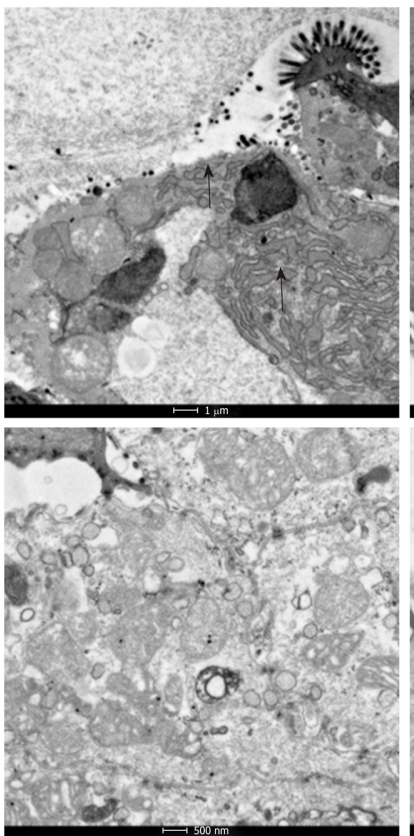

Model control group

$9300 x$
Mild moxibustion group 4800x
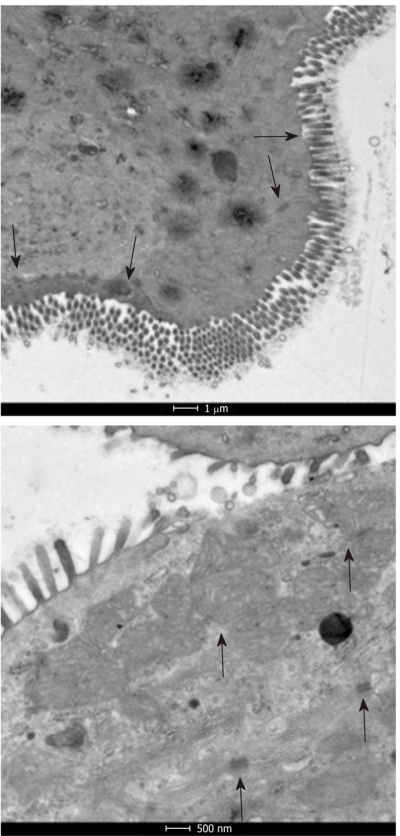

Mild moxibustion group $9300 x$
Sham moxibustion group $4800 \times$

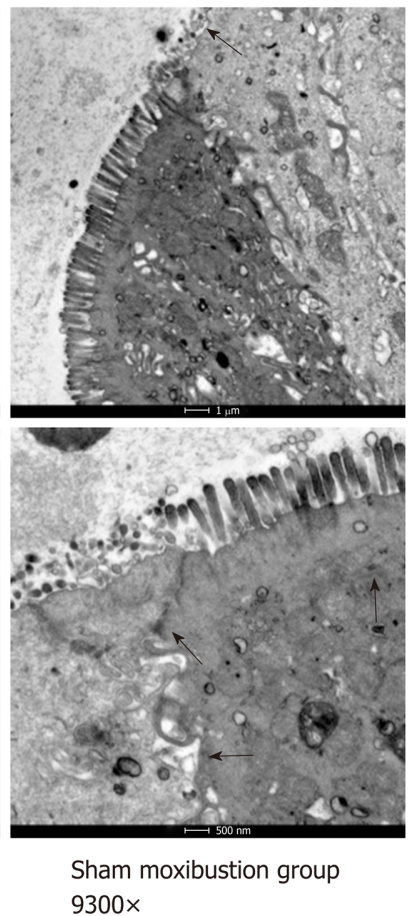

Figure 4 Effects of mild moxibustion on colonic ultrastructure of rats with post-infectious/post-inflammatory irritable bowel syndrome.

increasing the mRNA expression of NLRP6, but statistical significance was observed between these two groups in increasing the protein expression of NLRP6 $(P<0.01)$. The mRNA and protein expression of ASC and Caspase- 1 in the mild moxibustion group was significantly lower than that of the model control group $(P<0.01)$. NLRP6, ASC, and Caspase-1 mRNA and protein expression in the sham moxibustion group was similar to that of the model control group.

Compared with the sham moxibustion group, the NLRP6 mRNA $(P<0.05)$ and protein expression $(P<0.01)$ in colonic tissue of the mild moxibustion group increased significantly, while the ASC and Caspase-1 mRNA $(P<0.01)$ and protein expression $(P<0.01)$ significantly decreased (Figure 7$)$. Moreover, the expression locations of NLRP6, ASC, and Caspase-1 were mostly distributed in the cytoplasm of mucosal cells. The normal and mild moxibustion groups had higher NLRP6 expression intensity but lower ASC and Caspase-1 expression intensity than the model and sham moxibustion groups (Figure 8). These findings indicated that mild moxibustion, rather than sham moxibustion, could remarkably enhance the protein expression of NLRP6 and inhibit the mRNA and protein expression of ASC and Caspase- 1 in the PI-IBS rat model.

\section{The $m R N A$ and protein expression of $I L-1 \beta$ and IL-18}

The IL-1 $\beta$ and IL-18 mRNA and protein expression was significantly increased in the model control group $(P<0.01)$ compared with the normal control group. However, the mild moxibustion group displayed significantly lower expression levels of IL-1 $\beta$ and IL-18 mRNA $(P<0.01)$ and protein $(P<0.01)$, while the sham moxibustion group had similar expression levels of IL-1 $\beta$ and IL-18 mRNA and protein compared with model control group. The IL-1 $\beta$ and IL-18 mRNA and protein expression in the mild moxibustion group was significantly decreased compared with that of the sham moxibustion group $(P<0.01)$ (Figure 9$)$. These suggested that mild moxibustion could significantly inhibit the IL-1 $\beta$ and IL-18 mRNA and protein expression in intestinal tissues of PI-IBS rats, and exhibit a better effect than sham moxibustion in improving IL-1 $\beta$ and IL-18 expression.

\section{The $m R N A$ and protein expression of ITLN1 and RELM $\beta$}

Compared with the normal control group, the mRNA expression level of ITLN1 in the model control group was significantly lower $(P<0.01)$ while the mRNA expression of RELM $\beta$ was higher $(P<0.01)$; the protein expression of RELM $\beta$ also increased but without statistical significance. Compared with the model control group, the mRNA 

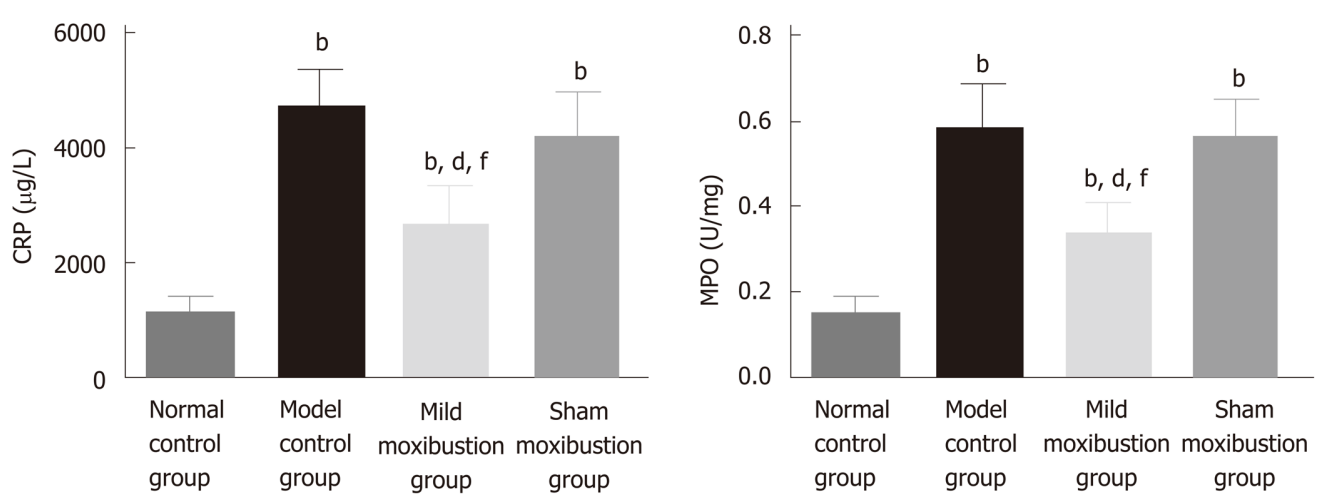

Figure 5 Effects of mild moxibustion on serum C-reactive protein levels and colonic myeloperoxidase activities in post-infectious/post-inflammatory irritable bowel syndrome rats in each group. A: Serum C-reactive protein levels; B: Myeloperoxidase activities. ${ }^{b} P<0.01$ vs normal control group; ${ }^{d} P<0.01$ vs model control group; ${ }^{\mathrm{f}} P<0.01$ vs sham moxibustion group. CRP: C-reactive protein; MPO: Myeloperoxidase.

expression of ITLN1 in the mild moxibustion group was notably higher $(P<0.05)$, while the mRNA expression of RELM $\beta$ was notably lower $(P<0.01)$; the protein expression of RELM $\beta$ was decreased without statistical significance. The mRNA and protein expression levels of ITLN1 and RELM $\beta$ in the sham moxibustion group were similar to those of the model control group.

Compared with the sham moxibustion group, the mRNA expression of ITLN1 in the mild moxibustion group was significant higher $(P<0.01)$ while the mRNA and protein expression of RELM $\beta$ was significant lower $(P<0.05)$. The protein expression of ILTN1 in the four groups varied but without statistical significance (Figure 10). These results suggested that mild moxibustion could remarkably increase the mRNA expression of ITLN1 whereas the mRNA expression of RELM $\beta$ in colon tissues of PIIBS rats was inhibited. Therefore, mild moxibustion showed a better treatment effect than sham moxibustion.

\section{Correlation of selected bacteria and NLRP6 inflammasome signaling}

The relative DNA abundances of Lactobacillus, Bifidobacteria, and Faecalibacterium prausnitzii in feces of rats in each group were shown to have positive correlations with the mRNA and protein expression of NLRP6 in the colon, and have negative correlations with those of ASC and Caspase- 1 in the colon. The relative DNA abundance of Escherichia coli in feces of rats in each group were showed to have negative correlations with the mRNA and protein expression of NLRP6 in the colon, and positive correlations with those of ASC and Caspase- 1 in the colon (Table 3).

\section{DISCUSSION}

In this study, we demonstrated that mild moxibustion on bilateral Tianshu (ST 25) and Zusanli (ST 36) points regulated visceral hypersensitivity in rats with TNBSinduced PI-IBS. The possible events behind these effects may include modulating the intestinal microbiota and NLRP6 inflammasome signaling. A close association between regulating selected bacteria and NLRP6 inflammasome signaling was linked to illustrate a possible way for the therapeutic effect of mild moxibustion on PI-IBS and to provide an effective therapeutic plan for moxibustion treatment of PI-IBS. Compared with the model control group, mild moxibustion treatment significantly lowered AWR scores under 20, 40, and $60 \mathrm{mmHg}$ pressure stimulation, while sham acupuncture did not. These results indicated that mild moxibustion is effective in downregulating gut sensitivity and increasing pain threshold in IBS.

The PI-IBS rats showed low-grade intestinal inflammation after successful establishment of the rat model. Mild moxibustion improved histological and ultrastructural features of the colon, serum CRP levels, and colonic MPO activities. Specifically, the colon of rats in the mild moxibustion group had smooth mucous membrane with mucosal rugae in a clear and integral shape and a slightly thicker bowel wall, clear mucosa without inflammatory infiltration, and some mildly congested and swollen submucosa. The damage caused by TNBS was alleviated compared to that of the model control group. Transmission electron microscopic images showed that colon villi of rats in the mild moxibustion group were neat with regular shape and equal length. There were no significant increase in the epithelial 

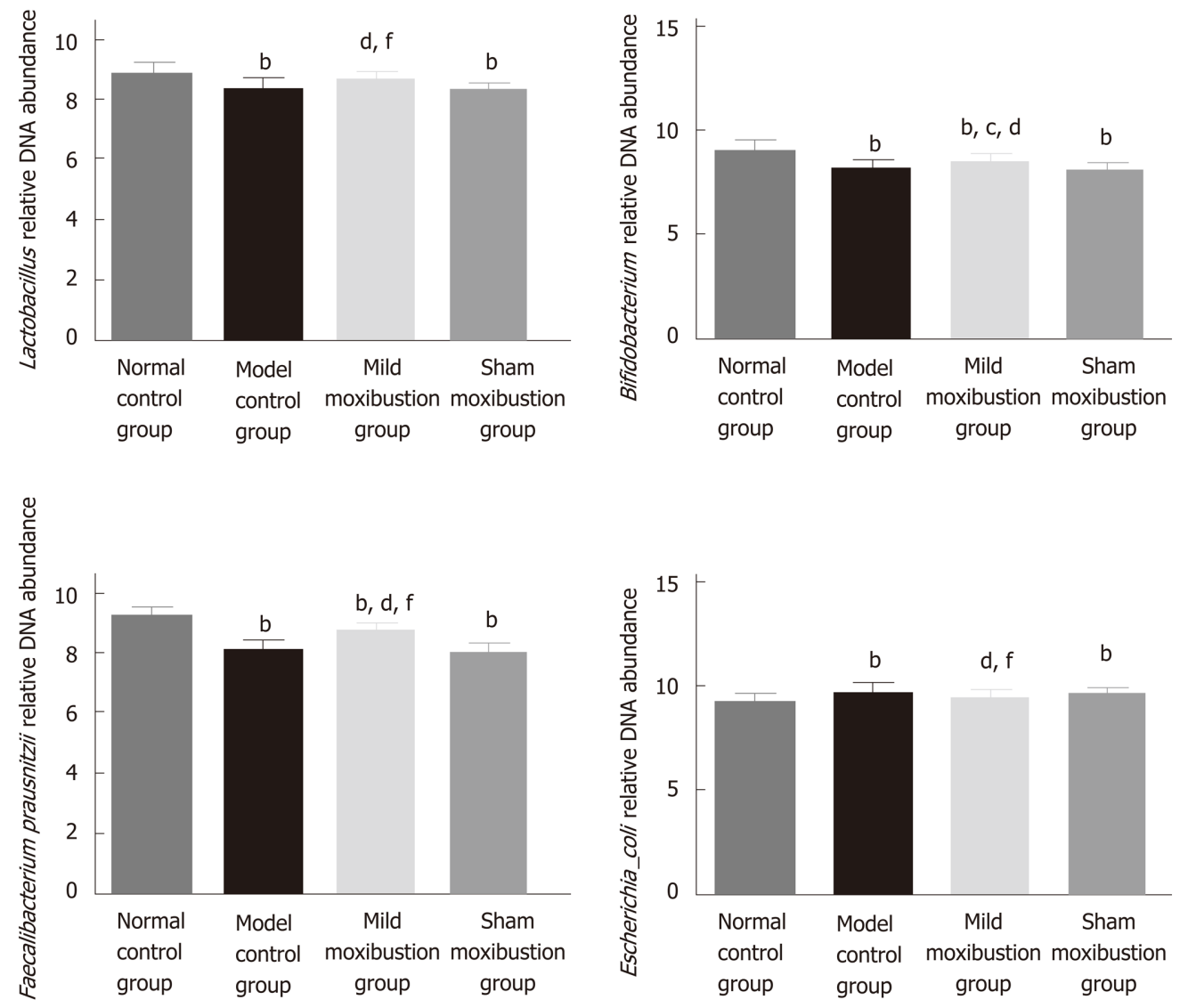

Figure 6 Effects of mild moxibustion on the relative DNA abundances of targeted bacteria in feces of post-infectious/post-inflammatory irritable bowel syndrome rats in each group. A: Relative DNA abundance of Lactobacillus; B: Relative DNA abundance of Bifidobacterium; C: Relative DNA abundance of Faecalibacterium prausnitzii; D: Relative DNA abundance of Escherichia coli. ${ }^{\mathrm{b}} P<0.01$ vs normal control group; ${ }^{\mathrm{c}} P<0.05$ and ${ }^{\mathrm{d}} P<0.01$ vs model control group; ${ }^{\mathrm{f}} P<$ 0.01 vs sham moxibustion group.

cell gaps, the shape of mitochondria and cristae were regular and clear, and the junctions of the intestinal epithelial cells were tight. Collectively, mild moxibustion effectively relieved colonic mucosal damage and ameliorated low-grade inflammation in the PI-IBS model.

Serum CRP levels and colonic MPO activities are generally used to evaluate the degree of inflammation ${ }^{[33-35]}$. Menees et al ${ }^{[33]}$ claimed that the results of their metaanalysis indicated that the diagnostic reliability of IBS could be improved by comprehensive consideration of both IBS symptoms and serum CRP level. Hod et al ${ }^{[34]}$ found that the average CRP level of 242 IBS patients was significantly higher than that of 244 healthy subjects. By using a TNBS-induced chronic visceral pain model in mice, Campaniello et $a l^{[35]}$ found that the MPO activity of the model control group was significantly increased. Similarly, the increased serum CRP level and colonic MPO activity of the PI-IBS rats in this study are consistent with the previous studies. After mild moxibustion treatment, serum CRP level and colonic MPO activity of the mild moxibustion group were remarkably decreased compared with those of the model and sham moxibustion groups, indicating that mild moxibustion effectively decreased the intestinal low-grade inflammation in PI-IBS rats.

We also explored whether mild moxibustion affects certain gut microbes. Previous studies revealed that the abundance of Escherichia coli was significantly increased while the relative DNA abundances of Lactobacillus and Bifidobacteria were remarkably decreased in IBS patients, compared with healthy subjects ${ }^{[36]}$. Lactobacillus and Bifidobacteria were found to relieve visceral hypersensitivity and inflammation in PIIBS rats ${ }^{[37]}$. Faecalibacterium prausnitzii had an anti-inflammatory effect as the cultural supernatant could ameliorate colitis ${ }^{[38]}$. Therefore, we chose to evaluate Lactobacillus, Bifidobacteria, Faecalibacterium prausnitzii, and Escherichia coli in this study. We found that the relative DNA abundances of Lactobacillus, Bifidobacteria, and Faecalibacterium prausnitzii in gut microbiome of rat feces were increased after mild moxibustion, while the abundance of Escherichia coli was decreased after the treatment. These results demonstrated that mild moxibustion was able to increase the relative DNA abundances of probiotic bacteria, decrease harmful bacteria, and balance the bacteria 

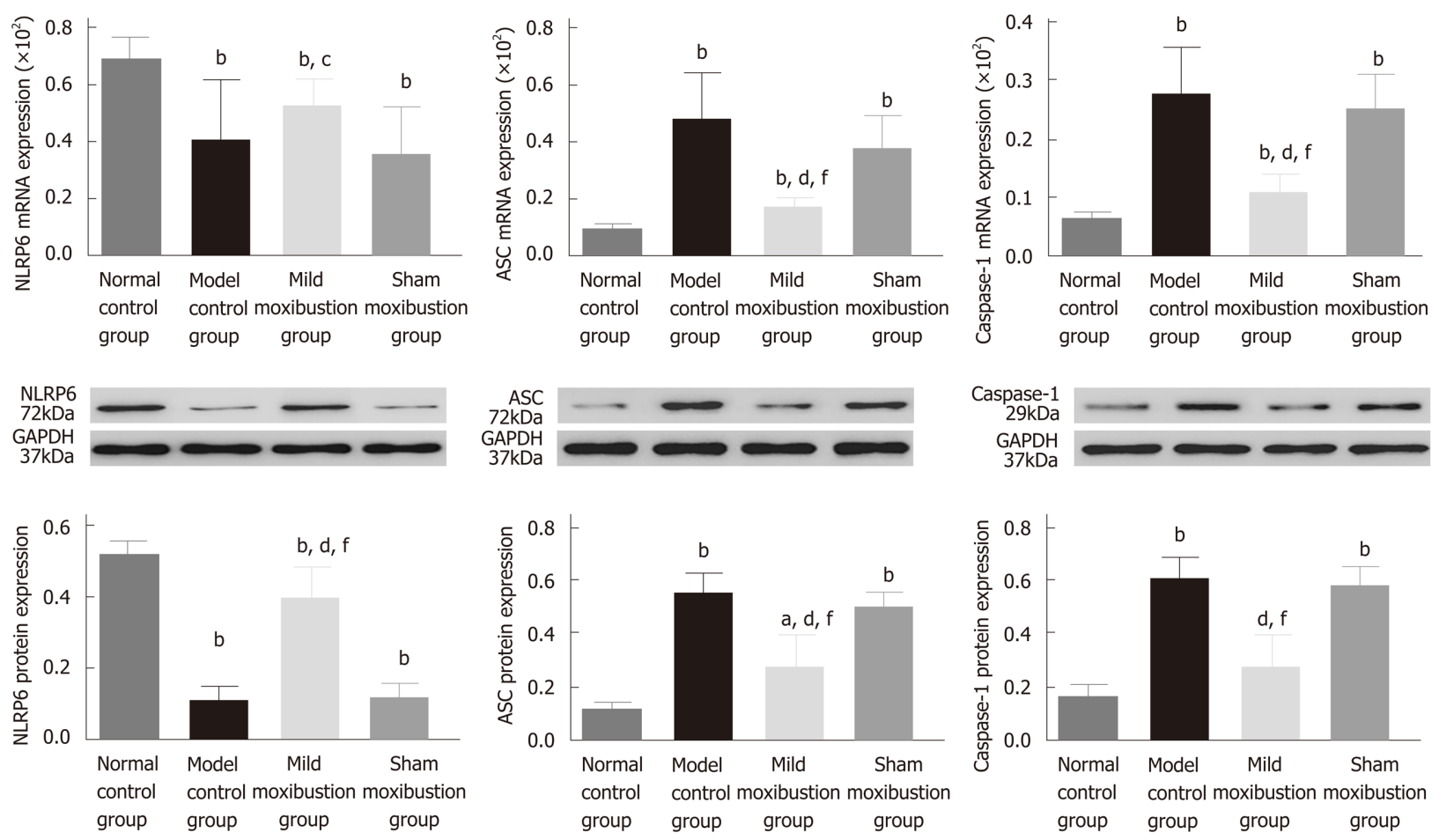

Figure 7 Effects of mild moxibustion on the mRNA and protein expression of NLRP6, ASC, and Caspase-1 in the colon of post-infectious/postinflammatory irritable bowel syndrome rats in each group. A: The mRNA expression levels of NLRP6, ASC, and Caspase-1; B: The protein expression of NLRP6, ASC, and Caspase-1. ${ }^{\mathrm{a}} P<0.05$ and ${ }^{\mathrm{b}} P<0.01$ vs normal control group; ${ }^{\mathrm{d}} P<0.01$ vs model control group; ${ }^{\mathrm{e}} P<0.05$ and $\mathrm{f} P<0.01$ vs sham moxibustion group.

composition of gut microbiota. The normal expression of NLRP6 and its ligands ASC and Caspase-1 in the intestinal mucosa is essential for the maintenance of intestinal microbiota homeostasis ${ }^{[1,202]}$. Abnormal expression of NLRP6 inflammasome signaling and its downstream cytokines (IL-1 $\beta$ and IL-18, antibacterial peptide ITLN1, and RELM $\beta$ ) in the intestinal mucosa plays important roles in the intestinal microbiota disturbance and low-grade inflammation in IBS patients. Analyses of the correlations between the relative DNA abundances of the four bacteria and the protein levels of NLRP6, ASC, and Caspase-1 showed significant correlations among them. The NLRP6 is a negative regulator that inhibits inflammatory signaling pathway ${ }^{[39]}$ and adjusts IL$1 \beta$ and IL-18 expression and other cytokines involved in the inflammatory and innate immune responses ${ }^{[10,41]}$.

The antibacterial peptide ITLN1 regulates intestinal immunity by affecting goblet cell protein expression, while RELM $\beta$ usually promotes the inflammatory response ${ }^{[13,14]}$. After mild moxibustion treatment, NLRP6 and ITLN1 mRNA and protein expression in the colonic tissue was increased, while the mRNA and protein expression levels of ASC, Caspase-1, and downstream cytokines IL-1 $\beta$, IL-18, and RELM $\beta$ were decreased. The effect of moxibustion on NLRP6 inflammasome signaling in this study was similar to that of Clostridium butyricum intervention ${ }^{[26]}$. Moreover, the results showed that mild moxibustion increased the expression of NLRP6 (the upstream regulatory factor), reduced the expression of ASC and Caspase1 to modulate NLRP6 inflammasome signaling, decreased the expression of downstream cytokines IL-1 $\beta$ and IL-18, promoted the mRNA and protein expression of ITLN1, and inhibited the mRNA and protein expression of RELM $\beta$. As a result, intestinal inflammation was ameliorated and intestinal homeostasis was maintained.

The present study still has some limitations. We only explored four bacterial species from among various gut microbes that can affect intestinal low-grade inflammation and visceral hypersensitivity. Additionally, inhibitors and gene knockout rat models were not applied in this study to measure the effects of mild moxibustion on NLRP6 inflammasome signaling. In the future, gene sequencing technology will be introduced to investigate the mechanisms of mild moxibustion in regulating gut microbiota, and the effect of mild moxibustion on NLRP6 inflammasome signaling will be tested. This study revealed that mild moxibustion inhibited intestinal low-grade inflammation via regulating the relative abundance of gut microbiota and NLRP6 inflammasome signaling, which may be an important event of mild moxibustion in relieving visceral hypersensitivity in PI-IBS. 
Table 3 Correlations between selective intestinal microbes and mRNA and protein expression of NLRP6, ASC, and Caspase-1

\begin{tabular}{lllllllll}
\hline & \multicolumn{2}{l}{ Lactobacillus } & \multicolumn{2}{c}{ Bifidobacterium } & \multicolumn{2}{c}{$\begin{array}{l}\text { Faecalibacterium_prau- } \\
\text { snitzii }\end{array}$} & \multicolumn{2}{c}{ Escherichia_coli } \\
\cline { 2 - 9 } & $r$ & $P$ & $r$ & $P$ & $r$ & $P$ & $r$ & $P$ \\
\hline NLRP6 mRNA & 0.550 & 0.000 & 0.542 & 0.000 & 0.624 & 0.000 & -0.495 & 0.000 \\
ASC mRNA & -0.641 & 0.000 & -0.633 & 0.000 & -0.747 & 0.000 & 0.432 & 0.005 \\
Caspase-1 mRNA & -0.656 & 0.000 & -0.688 & 0.000 & -0.737 & 0.000 & 0.716 & 0.000 \\
NLRP6 protein & 0.639 & 0.000 & 0.750 & 0.000 & 0.920 & 0.000 & -0.626 & 0.000 \\
ASC protein & -0.607 & 0.000 & -0.709 & 0.000 & -0.797 & 0.000 & 0.606 & 0.000 \\
Caspase-1 protein & -0.654 & 0.000 & -0.669 & 0.000 & -0.749 & 0.000 & 0.501 & 0.001 \\
\hline
\end{tabular}

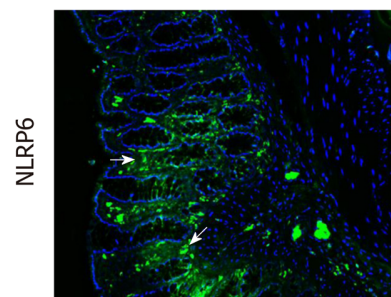

Normal control group

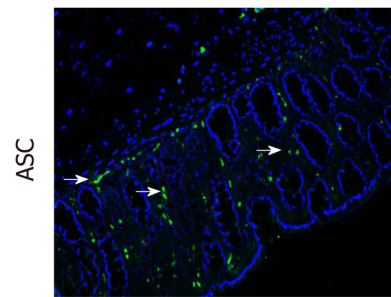

Normal control group

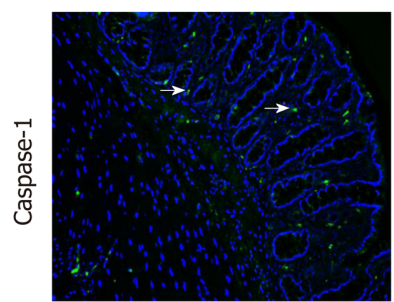

Normal control group

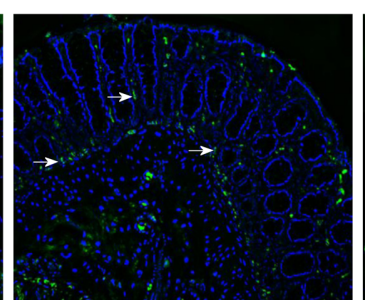

Model control group

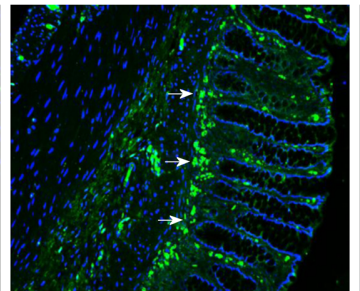

Model control group

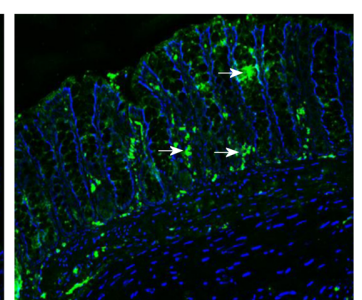

Model control group

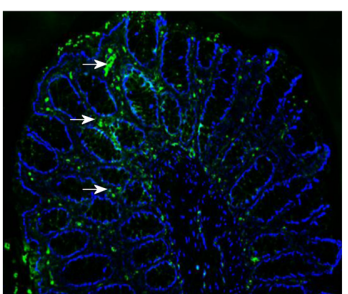

Mild moxibustion group

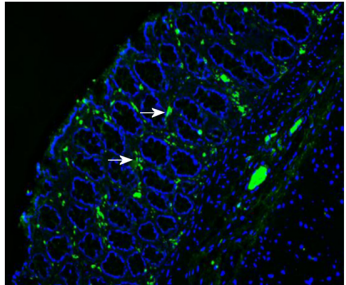

Mild moxibustion group

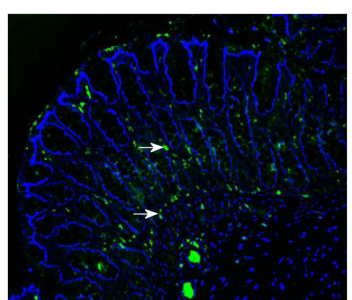

Mild moxibustion group

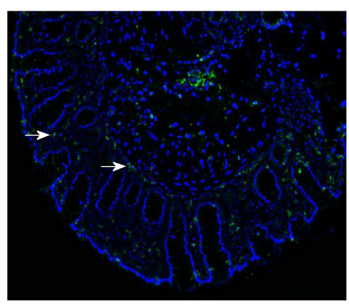

Sham moxibustion group

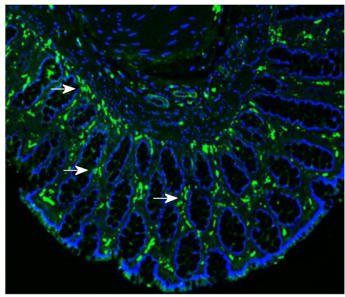

Sham moxibustion group

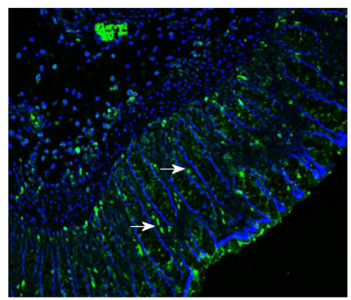

Sham moxibustion group

Figure 8 Effects of mild moxibustion on the protein expression of NLRP6, ASC, and Caspase-1 in the colon of post-infectious/post-inflammatory irritable bowel syndrome rats. NLRP6, ASC, and Caspase-1 are localized in the cytoplasm of mucosal cells in the mucosal layer of rats in each group. 

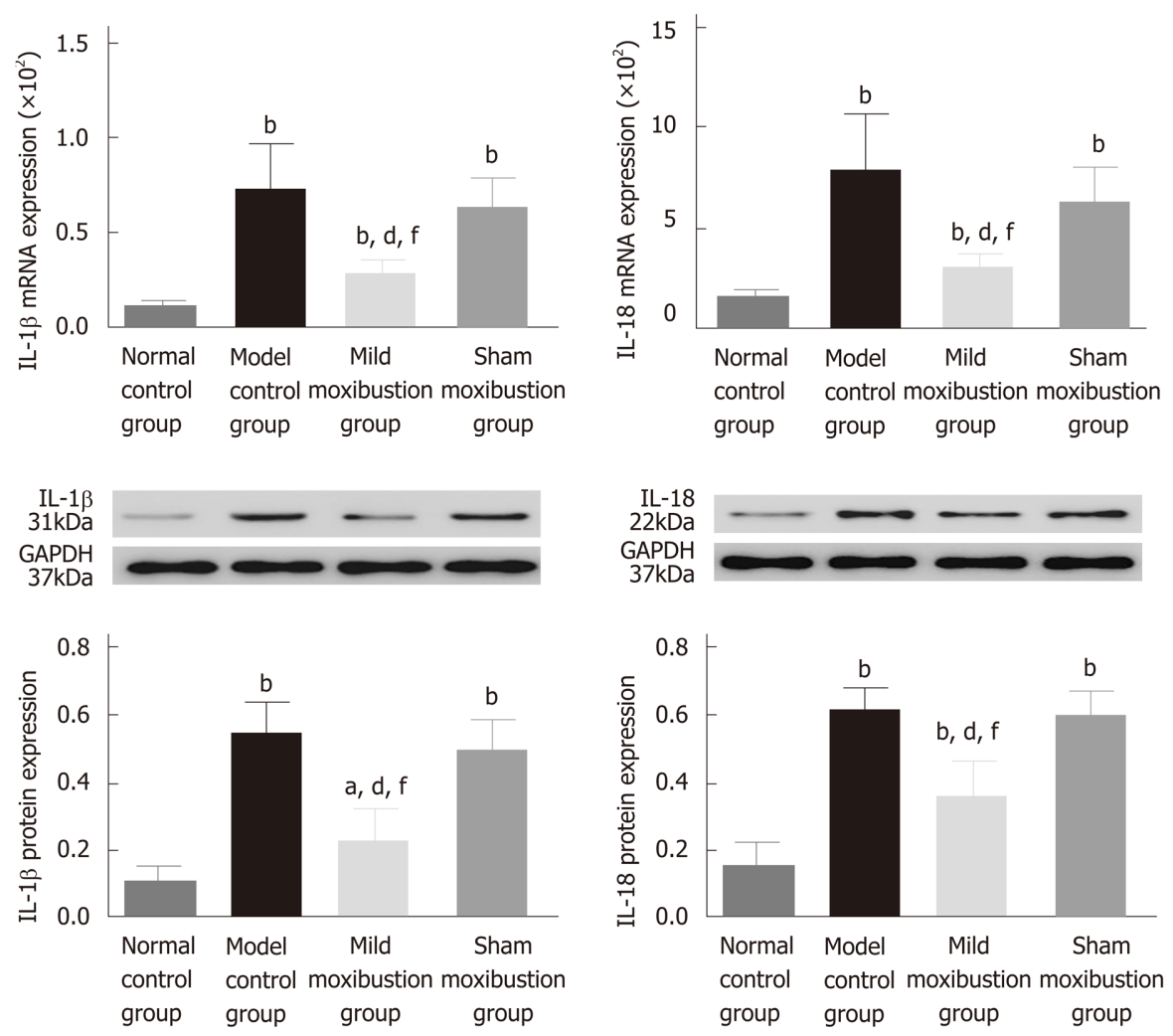

Figure 9 Effects of mild moxibustion on the mRNA and protein expression of IL-1 $\beta$ and IL-18 in the colon of post-infectious/post-inflammatory irritable bowel syndrome rats in each group. A: The mRNA expression levels of IL-1 $\beta$ and IL-18; B: Protein expression levels of IL- $1 \beta$ and IL-18. ${ }^{a} P<0.05$ and ${ }^{\text {b }} P<0.01$ vs normal control group; ${ }^{\mathrm{d}} P<0.01$ vs model control group; ${ }^{\mathrm{f}} P<0.01$ vs sham moxibustion group.
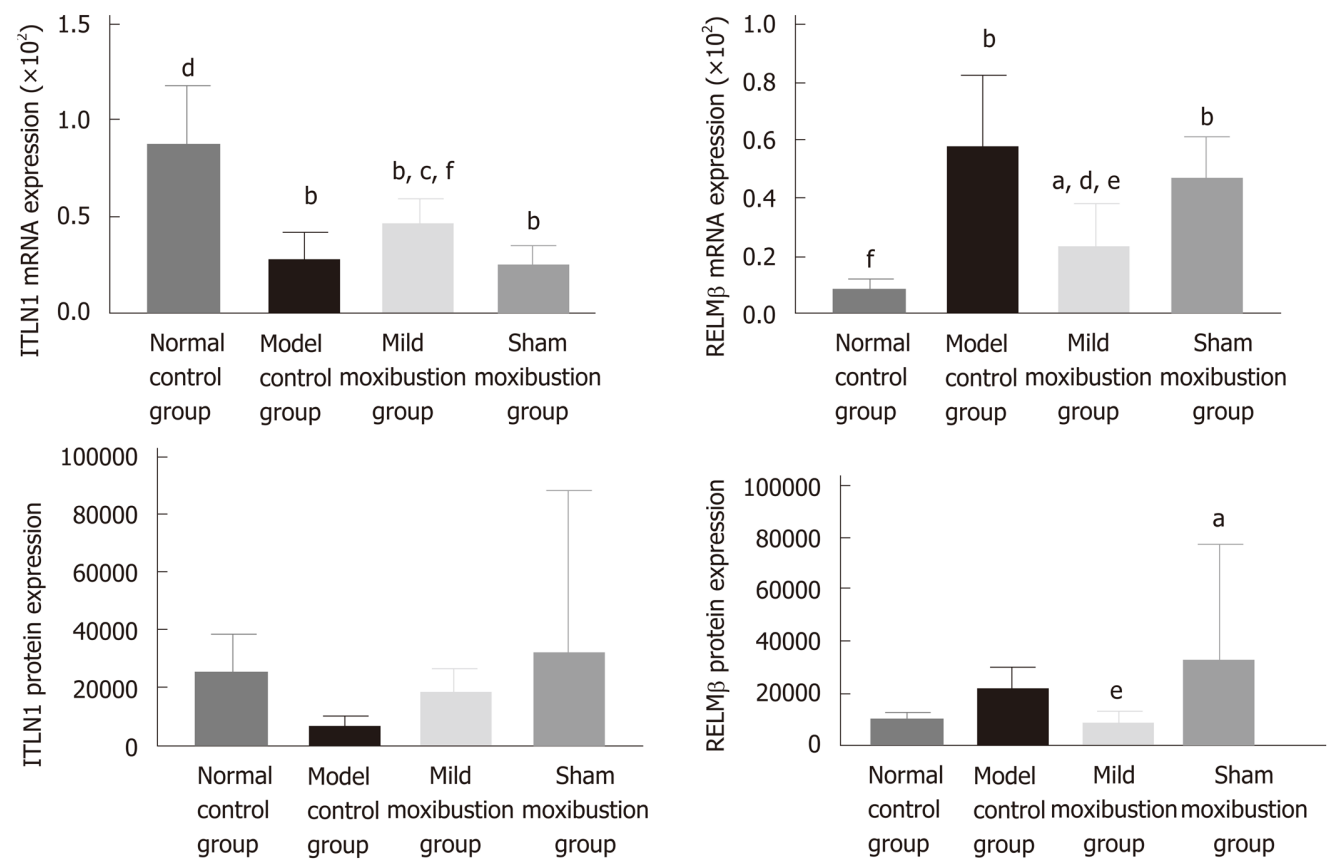

Figure 10 Effects of mild moxibustion on the mRNA and protein expression of ITLN1 and RELM $\beta$ in the colon of post-infectious/post-inflammatory irritable bowel syndrome rats in each group. A: The mRNA expression levels of ITLN1 and RELM $\beta$; B: Protein expression levels of ITLN1 and RELM 3 . a $P<0.05$ and ${ }^{b} P<$ 0.01 vs normal control group; ${ }^{\mathrm{d}} P<0.01$ vs model control group; ${ }^{\mathrm{e}} P<0.05$ and ${ }^{\mathrm{f}} P<0.01$ vs sham moxibustion group.

\section{ARTICLE HIGHLIGHTS}

\section{Research background}


Irritable bowel syndrome (IBS) is a common functional gastrointestinal (GI) disorder with associated symptoms of abdominal pain and distention, dysphoria, and/or changes of defecation shape. About one-third of refractory IBS cases are caused by GI infection/inflammation, known as post-infectious/post-inflammatory IBS (PI-IBS). Moxibustion has been shown to have a therapeutic effect on PI-IBS but whether moxibustion achieves its therapeutic effect by regulating the intestinal microbiota and host NLRP6 inflammatory signaling in PI-IBS remains unclear. Our previous study found that moxibustion decreased gut relative DNA abundances of Prevotella, Bacteroides, and Clostridium XI, increased the abundances of Lactobacillus and Clostridium XIVa, and improved the gut microbiota alpha diversity in a chronic visceral pain model of IBS in rats.

\section{Research motivation}

The hypothesis behind this study is that moxibustion could relieve the low-grade GI inflammation and alleviate visceral hypersensitivity of PI-IBS by regulating intestinal microbes and controlling NLRP6 inflammasome signaling.

\section{Research objectives}

The aim of this study was to investigate the possible events behind the therapeutic effect of moxibustion on PI-IBS rats via regulating gut microbiota and NLRP6 inflammasome signaling.

\section{Research methods}

Sixty rats were divided into a normal control group, a model control group, a mild moxibustion group, and a sham mild moxibustion group. PI-IBS rats in the mild moxibustion group were given $7 \mathrm{~d}$ of continuous moxibustion treatment. The sham group was given the same treatment as the mild moxibustion group except the moxa stick was not ignited. PI-IBS was induced with TNBS in rats. Moxibustion was applied to the bilateral Zusanli (ST36) and Tianshu (ST25). The abdominal withdrawal reflex (AWR) scores were assessed under the induction of balloon dilation for colorectal distension. Haematoxylin and eosin staining was assessed to evaluate the changes in the colonic histopathology. Serum C-reactive protein (CRP) levels and colonic myeloperoxidase (MPO) activities in colonic tissues of rats were measured by ELISA. 16S rDNA PCR was applied for testing the DNA relative abundance of selected intestinal bacteria. Western blot and qPCR were used to determine the protein and mRNA expression of NLRP6, ASC, Caspase-1, IL-1 $\beta$, IL-18, ITLN1, and RELM $\beta$.

\section{Research results}

Compared with the normal control group, the PI-IBS model control group had higher AWR scores, serum CRP levels, and colonic MPO activities. After treatment, the scores were decreased in the moxibustion group compared with the model control group. Mild moxibustion significantly increased the relative DNA abundances of intestinal Lactobacillus, Bifidobacterium, and Faecalibacterium prausnitzii but reduced the relative abundance of Escherichia coli in the gut of PI-IBS rats. Besides, mild moxibustion significantly enhanced the protein expression of NLRP6 and ITLN1 and inhibited the mRNA and protein expression of ASC, Caspase-1, IL-1 $\beta$, IL-18, and RELM $\beta$.

\section{Research conclusions}

This study revealed that mild moxibustion inhibits intestinal low-grade inflammation via regulating DNA abundances of gut microbes and NLRP6 inflammasome signaling, which may be an important mechanism of mild moxibustion in relieving visceral hypersensitivity in PI-IBS.

\section{Research perspectives}

Our findings may provide an experimental and scientific basis for the effective treatment of PIIBS by mild moxibustion.

\section{REFERENCES}

1 Liu J, Hou X. A review of the irritable bowel syndrome investigation on epidemiology, pathogenesis and pathophysiology in China. J Gastroenterol Hepatol 2011; 26: 88-93 [PMID: 21443718 DOI:

10.1111/j.1440-1746.2011.06641.x]

2 Barbara G, Cremon C, Pallotti F, De Giorgio R, Stanghellini V, Corinaldesi R. Postinfectious irritable bowel syndrome. J Pediatr Gastroenterol Nutr 2009; 48: S95-S97 [PMID: 19300138 DOI: 10.1097/MPG.0b013e3181a15e2e]

3 Wang H, Chang L. The Walkerton outbreak revisited at year 8: Predictors, prevalence, and prognosis of postinfectious irritable bowel syndrome. Gastroenterology 2011; 140: 726-8; discussion 728-9 [PMID: 21182958 DOI: 10.1053/j.gastro.2010.12.008]

4 Spiller R, Garsed K. Postinfectious irritable bowel syndrome. Gastroenterology 2009; 136: 1979-1988 [PMID: 19457422 DOI: 10.1053/j.gastro.2009.02.074]

5 Sinagra E, Pompei G, Tomasello G, Cappello F, Morreale GC, Amvrosiadis G, Rossi F, Lo Monte AI, Rizzo AG, Raimondo D. Inflammation in irritable bowel syndrome: Myth or new treatment target? World J Gastroenterol 2016; 22: 2242-2255 [PMID: 26900287 DOI: 10.3748/wjg.v22.i7.2242]

6 Spiller R, Garsed K. Infection, inflammation, and the irritable bowel syndrome. Dig Liver Dis 2009; 41: 844-849 [PMID: 19716778 DOI: 10.1016/j.dld.2009.07.007]

7 Sundin J, Rangel I, Fuentes S, Heikamp-de Jong I, Hultgren-Hörnquist E, de Vos WM, Brummer RJ. Altered faecal and mucosal microbial composition in post-infectious irritable bowel syndrome patients correlates with mucosal lymphocyte phenotypes and psychological distress. Aliment Pharmacol Ther 
2015; 41: 342-351 [PMID: 25521822 DOI: 10.1111/apt.13055]

8 Jalanka-Tuovinen J, Salojärvi J, Salonen A, Immonen O, Garsed K, Kelly FM, Zaitoun A, Palva A, Spiller RC, de Vos WM. Faecal microbiota composition and host-microbe cross-talk following gastroenteritis and in postinfectious irritable bowel syndrome. Gut 2014; 63: 1737-1745 [PMID: 24310267 DOI: 10.1136/gutjnl-2013-305994]

9 Barman M, Unold D, Shifley K, Amir E, Hung K, Bos N, Salzman N. Enteric salmonellosis disrupts the microbial ecology of the murine gastrointestinal tract. Infect Immun 2008; 76: 907-915 [PMID: 18160481 DOI: 10.1128/IAI.01432-07]

10 Joo YE. Alteration of fecal microbiota in patients with postinfectious irritable bowel syndrome. $J$ Neurogastroenterol Motil 2015; 21: 135-137 [PMID: 25611066 DOI: 10.5056/jnm14133]

11 Kanneganti TD, Lamkanfi M, Núñez G. Intracellular NOD-like receptors in host defense and disease. Immunity 2007; 27: 549-559 [PMID: 17967410 DOI: 10.1016/j.immuni.2007.10.002]

12 Levy M, Thaiss CA, Zeevi D, Dohnalová L, Zilberman-Schapira G, Mahdi JA, David E, Savidor A, Korem T, Herzig Y, Pevsner-Fischer M, Shapiro H, Christ A, Harmelin A, Halpern Z, Latz E, Flavell RA, Amit I, Segal E, Elinav E. Microbiota-Modulated Metabolites Shape the Intestinal Microenvironment by Regulating NLRP6 Inflammasome Signaling. Cell 2015; 163: 1428-1443 [PMID: 26638072 DOI: 10.1016/j.cell.2015.10.048]

13 Owen RP, White MJ, Severson DT, Braden B, Bailey A, Goldin R, Wang LM, Ruiz-Puig C, Maynard ND, Green A, Piazza P, Buck D, Middleton MR, Ponting CP, Schuster-Böckler B, Lu X. Single cell RNAseq reveals profound transcriptional similarity between Barrett's oesophagus and oesophageal submucosal glands. Nat Commun 2018; 9: 4261 [PMID: 30323168 DOI: 10.1038/s41467-018-06796-9]

14 Brown K, Abbott DW, Uwiera RRE, Inglis GD. Removal of the cecum affects intestinal fermentation, enteric bacterial community structure, and acute colitis in mice. Gut Microbes 2018; 9: 218-235 [PMID: 29227180 DOI: 10.1080/19490976.2017.1408763]

15 Lacy BE. Review article: An analysis of safety profiles of treatments for diarrhoea-predominant irritable bowel syndrome. Aliment Pharmacol Ther 2018; 48: 817-830 [PMID: 30194692 DOI: 10.1111/apt.14948] Tang B, Zhang J, Yang Z, Lu Y, Xu Q, Chen X, Lin J. Moxibustion for Diarrhea-Predominant Irritable Bowel Syndrome: A Systematic Review and Meta-Analysis of Randomized Controlled Trials. Evid Based Complement Alternat Med 2016; 2016: 5105108 [PMID: 27293460 DOI: 10.1155/2016/5105108]

17 Park JW, Lee BH, Lee H. Moxibustion in the management of irritable bowel syndrome: Systematic review and meta-analysis. BMC Complement Altern Med 2013; 13: 247 [PMID: 24088418 DOI: 10.1186/1472-6882-13-247]

18 Wang X, Qi Q, Wang Y, Wu H, Jin X, Yao H, Jin D, Liu Y, Wang C. Gut microbiota was modulated by moxibustion stimulation in rats with irritable bowel syndrome. Chin Med 2018; 13: 63 [PMID: 30574173 DOI: 10.1186/s13020-018-0220-y]

19 Elinav E, Strowig T, Kau AL, Henao-Mejia J, Thaiss CA, Booth CJ, Peaper DR, Bertin J, Eisenbarth SC, Gordon JI, Flavell RA. NLRP6 inflammasome regulates colonic microbial ecology and risk for colitis. Cell 2011; 145: 745-757 [PMID: 21565393 DOI: 10.1016/j.cell.2011.04.022]

20 Chen GY, Liu M, Wang F, Bertin J, Núñez G. A functional role for Nlrp6 in intestinal inflammation and tumorigenesis. J Immunol 2011; 186: 7187-7194 [PMID: 21543645 DOI: 10.4049/jimmunol.1100412]

21 Qin HY, Xiao HT, Wu JC, Berman BM, Sung JJ, Bian ZX. Key factors in developing the trinitrobenzene sulfonic acid-induced post-inflammatory irritable bowel syndrome model in rats. World J Gastroenterol 2012; 18: 2481-2492 [PMID: 22654445 DOI: 10.3748/wjg.v18.i20.2481]

22 Al-Chaer ED, Kawasaki M, Pasricha PJ. A new model of chronic visceral hypersensitivity in adult rats induced by colon irritation during postnatal development. Gastroenterology 2000; 119: 1276-1285 [PMID: 11054385 DOI: 10.1053/gast.2000.19576]

23 Li ZR. Experimental Acupuncture. 2ed. Chinese Press of Traditional Chinese Medicine. 2007; 255-257

24 Liu HR, Bao CH, Wang CY, Yan YL, Li J, Hu ZH, Shi Y, Jin XM, Zeng XQ, Wu HG. Long-term effect of moxibustion on irritable bowel syndrome: A randomized clinical trial. Gastroenterology 2018; 154: S196 [DOI: 10.1016/S0016-5085(18)31057-6]

25 Bao C, Zhang J, Liu J, Liu H, Wu L, Shi Y, Li J, Hu Z, Dong Y, Wang S, Zeng X, Wu H. Moxibustion treatment for diarrhea-predominant irritable bowel syndrome: Study protocol for a randomized controlled trial. BMC Complement Altern Med 2016; 16: 408 [PMID: 27776494 DOI: 10.1186/s12906-016-1386-4]

26 Wallace JL, MacNaughton WK, Morris GP, Beck PL. Inhibition of leukotriene synthesis markedly accelerates healing in a rat model of inflammatory bowel disease. Gastroenterology 1989; 96: 29-36 [PMID: 2535830 DOI: 10.1016/0016-5085(89)90760-9]

27 Park MY, Ji GE, Sung MK. Dietary kaempferol suppresses inflammation of dextran sulfate sodiuminduced colitis in mice. Dig Dis Sci 2012; 57: 355-363 [PMID: 21901258 DOI: 10.1007/s10620-011-1883-8]

28 Zhao K, Yu L, Wang X, He Y, Lu B. Clostridium butyricum regulates visceral hypersensitivity of irritable bowel syndrome by inhibiting colonic mucous low grade inflammation through its action on NLRP6. Acta Biochim Biophys Sin (Shanghai) 2018; 50: 216-223 [PMID: 29329362 DOI: 10.1093/abbs/gmx138]

29 Duboc H, Rainteau D, Rajca S, Humbert L, Farabos D, Maubert M, Grondin V, Jouet P, Bouhassira D, Seksik P, Sokol H, Coffin B, Sabaté JM. Increase in fecal primary bile acids and dysbiosis in patients with diarrhea-predominant irritable bowel syndrome. Neurogastroenterol Motil 2012; 24: 513-520, e246-e247 [PMID: 22356587 DOI: 10.1111/j.1365-2982.2012.01893.x]

30 Rajilić-Stojanović M, Biagi E, Heilig HG, Kajander K, Kekkonen RA, Tims S, de Vos WM. Global and deep molecular analysis of microbiota signatures in fecal samples from patients with irritable bowel syndrome. Gastroenterology 2011; 141: 1792-1801 [PMID: 21820992 DOI: 10.1053/j.gastro.2011.07.043]

31 Wang XM, Lu Y, Wu LY, Yu SG, Zhao BX, Hu HY, Wu HG, Bao CH, Liu HR, Wang JH, Yao Y, Hua XG, Guo HY, Shen LR. Moxibustion inhibits interleukin-12 and tumor necrosis factor alpha and modulates intestinal flora in rat with ulcerative colitis. World J Gastroenterol 2012; 18: 6819-6828 [PMID: 23239920 DOI: 10.3748/wjg.v18.i46.6819]

32 Bao CH, Wu LY, Shi Y, Wu HG, Liu HR, Zhang R, Yu LQ, Wang JH. Moxibustion down-regulates colonic epithelial cell apoptosis and repairs tight junctions in rats with Crohn's disease. World J Gastroenterol 2011; 17: 4960-4970 [PMID: 22174545 DOI: 10.3748/wjg.v17.i45.4960]

33 Menees SB, Powell C, Kurlander J, Goel A, Chey WD. A meta-analysis of the utility of C-reactive protein, erythrocyte sedimentation rate, fecal calprotectin, and fecal lactoferrin to exclude inflammatory bowel disease in adults with IBS. Am J Gastroenterol 2015; 110: 444-454 [PMID: 25732419 DOI: 10.1038/ajg.2015.6]

34 Hod K, Ringel-Kulka T, Martin CF, Maharshak N, Ringel Y. High-sensitive C-Reactive Protein as a 
Marker for Inflammation in Irritable Bowel Syndrome. J Clin Gastroenterol 2016; 50: 227-232 [PMID: 25930973 DOI: 10.1097/MCG.0000000000000327]

35 Campaniello MA, Harrington AM, Martin CM, Ashley Blackshaw L, Brierley SM, Hughes PA. Activation of colo-rectal high-threshold afferent nerves by Interleukin-2 is tetrodotoxin-sensitive and upregulated in a mouse model of chronic visceral hypersensitivity. Neurogastroenterol Motil 2016; 28: 5463 [PMID: 26468044 DOI: 10.1111/nmo.12696]

36 Zhong W, Lu X, Shi H, Zhao G, Song Y, Wang Y, Zhang J, Jin Y, Wang S. Distinct Microbial Populations Exist in the Mucosa-associated Microbiota of Diarrhea Predominant Irritable Bowel Syndrome and Ulcerative Colitis. J Clin Gastroenterol 2017 [PMID: 29210899 DOI 10.1097/MCG.0000000000000961]

37 Wang H, Gong J, Wang W, Long Y, Fu X, Fu Y, Qian W, Hou X. Are there any different effects of Bifidobacterium, Lactobacillus and Streptococcus on intestinal sensation, barrier function and intestinal immunity in PI-IBS mouse model? PLoS One 2014; 9: e90153 [PMID: 24595218 DOI: 10.1371/journal.pone.0090153]

38 Lozupone CA, Stombaugh JI, Gordon JI, Jansson JK, Knight R. Diversity, stability and resilience of the human gut microbiota. Nature 2012; 489: 220-230 [PMID: 22972295 DOI: 10.1038/nature11550]

39 Anand PK, Malireddi RK, Lukens JR, Vogel P, Bertin J, Lamkanfi M, Kanneganti TD. NLRP6 negatively regulates innate immunity and host defence against bacterial pathogens. Nature 2012; 488: 389-393 [PMID: 22763455 DOI: 10.1038/nature11250]

40 Kempster SL, Belteki G, Forhead AJ, Fowden AL, Catalano RD, Lam BY, McFarlane I, Charnock-Jones DS, Smith GC. Developmental control of the Nlrp6 inflammasome and a substrate, IL-18, in mammalian intestine. Am J Physiol Gastrointest Liver Physiol 2011; 300: G253-G263 [PMID: 21088234 DOI: 10.1152/ajpgi.00397.2010]

41 Lee SH, Stehlik C, Reed JC. Cop, a caspase recruitment domain-containing protein and inhibitor of caspase-1 activation processing. J Biol Chem 2001; 276: 34495-34500 [PMID: 11432859 DOI: 10.1074/jbc.m101415200] 


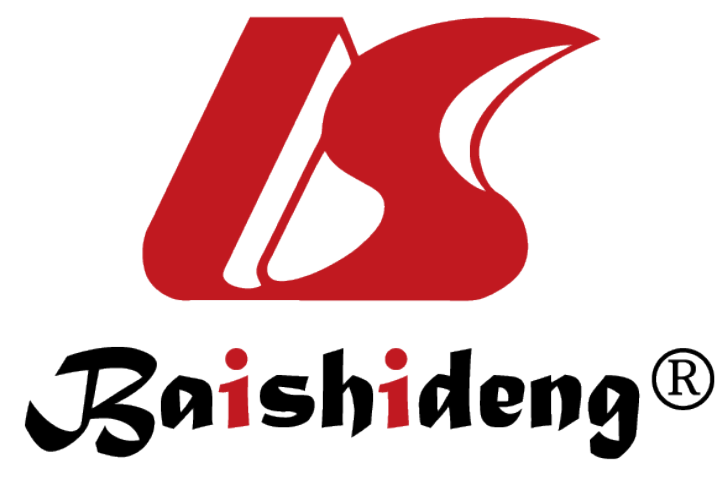

Published By Baishideng Publishing Group Inc

7041 Koll Center Parkway, Suite 160, Pleasanton, CA 94566, USA

Telephone: +1-925-2238242

Fax: +1-925-2238243

E-mail: bpgoffice@wjgnet.com

Help Desk:http://www.f6publishing.com/helpdesk

http://www.wjgnet.com

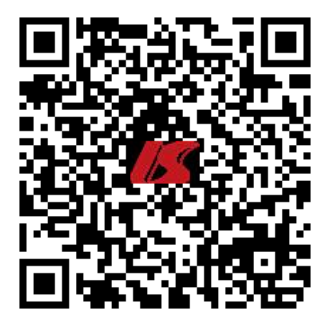

